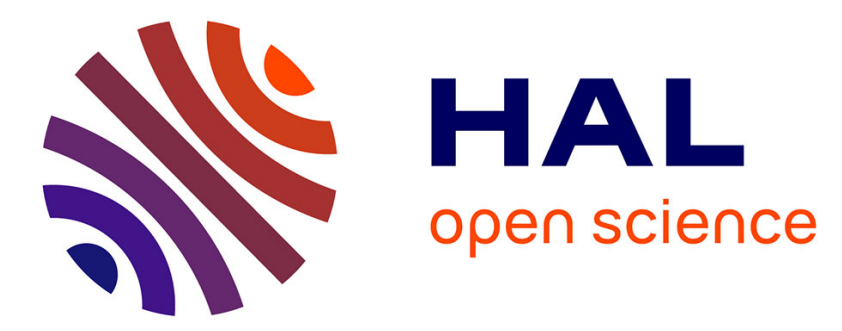

\title{
Nitrogen-Doped Carbon Dots/TiO2 Nanoparticle Composites for Photoelectrochemical Water Oxidation
}

Hui Luo, Stoichko Dimitrov, Matyas Daboczi, Ji-Seon Kim, Qian Guo, Yuanxing Fang, Marc Antoine Stoeckel, Paolo Samori, Oliver Fenwick, Ana Belen Jorge Sobrido, et al.

\section{To cite this version:}

Hui Luo, Stoichko Dimitrov, Matyas Daboczi, Ji-Seon Kim, Qian Guo, et al.. Nitrogen-Doped Carbon Dots/TiO2 Nanoparticle Composites for Photoelectrochemical Water Oxidation. ACS Applied Nano Materials, 2020, 3 (4), pp.3371-3381. 10.1021/acsanm.9b02412 . hal-02898851

\section{HAL Id: hal-02898851 https://hal.science/hal-02898851}

Submitted on 13 Jul 2020

HAL is a multi-disciplinary open access archive for the deposit and dissemination of scientific research documents, whether they are published or not. The documents may come from teaching and research institutions in France or abroad, or from public or private research centers.
L'archive ouverte pluridisciplinaire HAL, est destinée au dépôt et à la diffusion de documents scientifiques de niveau recherche, publiés ou non, émanant des établissements d'enseignement et de recherche français ou étrangers, des laboratoires publics ou privés. 


\title{
Nitrogen-doped Carbon Dots $/ \mathrm{TiO}_{2}$ Nanoparticle
}

\section{Composites for Photoelectrochemical Water}

\section{Oxidation}

\author{
Hui Luo, ${ }^{a, g}$ Stoichko Dimitrov, ${ }^{b, c}$ Matyas Daboczi, ${ }^{d}$ Ji-Seon Kim, ${ }^{d}$ Qian Guo, ${ }^{a}$ Yuanxing Fang, ${ }^{e}$ \\ Marc-Antoine Stoeckel, ${ }^{f}$ Paolo Samori,,${ }^{\prime}$ Oliver Fenwick, ${ }^{a}$ Ana Belen Jorge Sobrido, ${ }^{a}$ Xinchen \\ Wang $^{e}$ and Maria-Magdalena Titirici ${ }^{a, g}{ }^{*}$
}

a. School of Engineering and Materials Science, Queen Mary University of London, Mile End Road, E1 4NS, London, UK

b. SPECIFIC, College of Engineering, Swansea University SA2 7AX, Swansea, UK

c. School of Biological and Chemical Sciences, Queen Mary University of London, Mile End Road, E1 4NS, London, UK

d. Department of Physics and Centre for Plastic Electronics, Imperial College London, South Kensington Campus, SW7 2AZ, London, UK

e. State Key Laboratory of Photocatalysis on Energy and Environment, College of Chemistry, Fuzhou University, Fuzhou, 350116 P. R. China 
f. Université de Strasbourg, CNRS, ISIS, 8, allée Gaspard Monge, 67000, Strasbourg, France

g. Department of Chemical Engineering, Imperial College London, South Kensington Campus, SW7 2AZ, London, UK

Corresponding author e-mail: m.titirici@imperial.ac.uk

KEYWORDS: Carbon dots, Photoelectrocatalysis, Heterojunction, Charge transfer, Band structure

\begin{abstract}
Carbon dots on photoactive semiconductor nanomaterials have represented an effective strategy for enhancing their photoelectrochemical (PEC) activity. By carefully designing and manipulating carbon dots/support composite, a high photocurrent could be obtained. Currently, there is not much fundamental understanding of how the interaction between such materials can facilitate the reaction process. This hinders the wide applicability in PEC devices. To address this need of improving the fundamental understanding of carbon dots/semiconductor nanocomposite, we have taken the $\mathrm{TiO}_{2}$ case as a model semiconductor system with nitrogen-doped carbon dots (NCDs). We present here with in-depth investigation of the structural hybridization and energy transitions in the $\mathrm{NCDs} / \mathrm{TiO}_{2}$ photoelectrode via high-resolution scanning transmission microscopy (HRSTEM), electron energy loss spectroscopy (EELS), UV-Vis absorption, electrochemical impedance spectroscopy (EIS), Mott-Schottky (M-S), time-correlated single photon counting (TCSPC) and ultra-violet photoelectron spectroscopy (UPS), which shed some light on the charge transfer process at the carbon dots and $\mathrm{TiO}_{2}$ interface. We show that $\mathrm{N}$ doping in carbon dots can
\end{abstract}


effectively prolong the carrier lifetime, and the hybridisation of $\mathrm{NCDs}$ and $\mathrm{TiO}_{2}$ is able not only to extend $\mathrm{TiO}_{2}$ light response into the visible range but also to form heterojunction at the $\mathrm{NCDs} / \mathrm{TiO}_{2}$ interface with properly aligned band structure that allows a spatial separation of the charges. This work is arguably the first to report the direct probing of the band positions of carbon dots- $\mathrm{TiO}_{2}$ nanoparticle composite in a PEC system for understanding the energy transfer mechanism, demonstrating the favourable role of NCDs in the photocurrent response of $\mathrm{TiO}_{2}$ for water oxidation process. This study reveals the importance of combining structural, photophysical and electrochemical experiments to develop a comprehensive understanding of the nanoscale charge transfer processes between the carbon dots and their catalyst supports.

\section{Introduction}

Photoelectrochemical (PEC) water splitting for hydrogen and oxygen production represents a promising technology for the conversion of solar energy to clean and renewable chemical fuels. Since the first report on PEC water splitting in 1972 using $\mathrm{TiO}_{2}$ photoelectrode, ${ }^{1}$ many efforts have been made to improving the light conversion efficiency. To achieve the overall reaction, the water oxidation happening at photoanode is a crucial step as it requires higher energy input. Several approaches have been reported in the literature to improve the performance of the photoanode materials, such as heteroatom doping, ${ }^{2}$ nanostructring ${ }^{3}$ etc. Among those, constructing heterojunctions in nanoscale materials like $\mathrm{CdS} / \mathrm{TiO}_{2},{ }^{4-8}$ graphene/ $\mathrm{TiO}_{2},{ }^{9,10}$ carbon dots/ $\mathrm{TiO}_{2}{ }^{11-15}$ has been demonstrated to be an effective strategy. The enhanced PEC performance of the $\mathrm{CdS} / \mathrm{TiO}_{2}$ system is assigned to the electric-field-assisted charge transport at the interface with matched band alignments, which can improve the charge separation and prolong the photo-induced carrier lifetime. In the case of graphene or reduced graphene oxide, those 2D and zero bandgap 
materials serve as electron mediator when coupled with $\mathrm{TiO}_{2}$, allowing an accelerated electron migration at the interface.

Carbon dots with size less than $10 \mathrm{~nm}$ have been demonstrated to act as photosensitizers for enhancing the performance of heterogeneous photocatalysts, due to their adjustable band potentials, excellent and tunable light-harvesting ability, and electron transfer efficiency. ${ }^{12,16-20}$ When doped with nitrogen, ${ }^{13,21,22}$ carbon dots usually show an enhanced activity towards photodriven reactions both experimentally and theoretically. ${ }^{23,24}$ Accordingly, the utilisation of nitrogendoped carbon dots (NCDs) photosensitizers to facilitate PEC reactions started to attract attention. ${ }^{13,21,25}$ However, owing to the complexity of NCDs compare to CdS and graphene in terms of chemical structure and energy states, the mechanism of NCDs in improving the PEC performance is still not well understood and explained. ${ }^{12,17,26}$ Previous studies have indirectly demonstrated that the electronic coupling between the $\pi$ states of the CDs and the conduction band of $\mathrm{TiO}_{2}$ can form heterojunctions and impart the system for visible light absorption. The resulting heterojunction can efficiently separate the photo-generated electrons and holes, resulting in a lower recombination rate and a higher PEC activity. ${ }^{14}$ Those effects can be greatly influenced by the intrinsic properties of CDs. For instance, the graphitisation degree can affect the charge transfer process,${ }^{27}$ the different $\mathrm{N}$ doping configuration (amines, amides, pyridinic, quaternary, $\mathrm{N}$-oxides, etc.) can govern the light-harvesting ability, ${ }^{28}$ while the functionality would determine the interaction with supporting materials. ${ }^{16,29}$ Hence, it is of vital importance to develop a deeper understanding of the nanostructure of CDs and their interaction with the semiconductor materials and gain further insights on the dynamics of the charge exchange process at the materials interface. In this paper, we exploit a broad arsenal of complementary advanced characterisation technique to understand the morphology, structure, optical and electrochemical properties of chitosan derived 
NCDs at a fundamental level. Such studies reveal that N doping can effectively prolong the photoinduced carrier lifetime. A photoanode was prepared by decorating the as-synthesized NCDs onto a $\mathrm{TiO}_{2}$ mesoporous film, which is used as a model semiconductor material to study the NCDs/semiconductor interaction. A detailed structural and PEC analysis showed that the nanoparticle composite possesses an improved visible light response as well as charge separation/transport ability, which resulted in a higher photocurrent value. In-depth characterisation of the $\mathrm{NCD} / \mathrm{TiO}_{2}$ nanocomposite by methods such as Mott-Schottky analysis, photoelectron spectroscopy in air, Kelvin probe and ultra-violet photoelectron spectroscopy was employed to evaluate the energy levels. Combined with electrochemical impedance spectroscopy (EIS) and in-situ photoluminescence quenching by time-correlated single photon counting (TCSPC), we present here the detailed mechanism for the interfacial charge transfer process.

\section{Results and discussion}
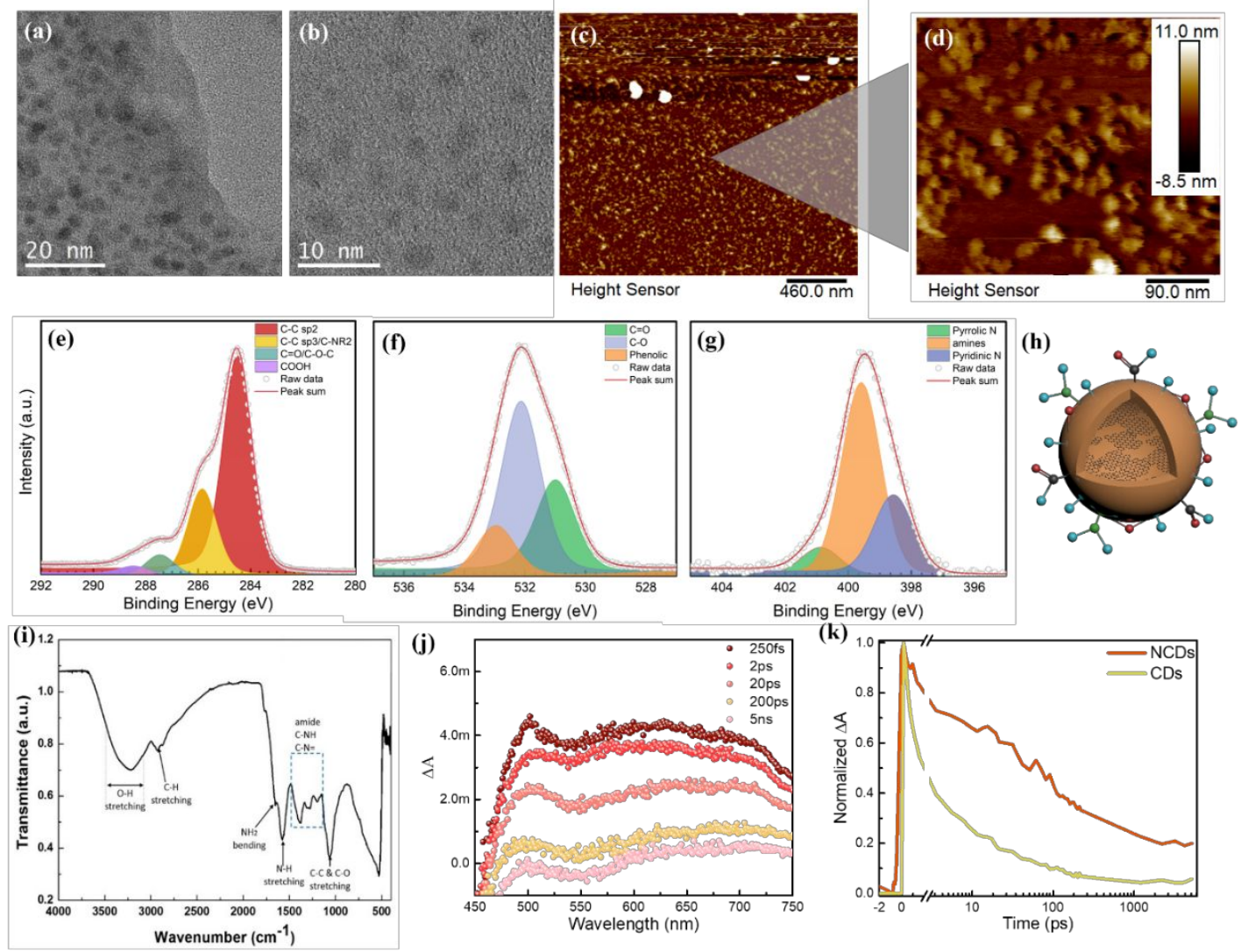
Figure 1 Structural features of as-prepared NCDs: TEM (a) and HR-TEM (b) images; (c) an overview AFM image on mica substrate (Z scale -6.0 to $7.9 \mathrm{~nm}$ ) and (d) high-resolution scanned image; XPS spectra: (e) C 1s, (f) O 1s, (g) N 1s and corresponding FTIR (i) spectrum; (h) a schematic structure based on the characterizations (atoms in red: $\mathrm{O}$, green: $\mathrm{N}$ and blue: $\mathrm{H}$ ); (j) fsTAS spectra at different time decays and $(k)$ normalized fs-TAS kinetics of NCDs and non-doped CDs measured at $500 \mathrm{~nm}$ (excitation wavelength: $375 \mathrm{~nm}$ ).

NCDs were synthesized by solvothermal carbonisation of chitosan in ethanol solvent (4\% w/v). Several works on using chitosan to produce NCDs have been reported earlier. ${ }^{30-32}$ Under mild conditions ( $\mathrm{HTC}$ with $180{ }^{\circ} \mathrm{C}$ ), the carbonisation and functionalisation will take place through chitosan dehydration, leading to the formation of NCDs. As illustrated in Figure S1, the precursor molecules go through decomposition to HMF and ammonia. The HMF molecule then go through ring opening to react with ammonia and form aminopentanals. Intermolecular condensation would occur at this stage in these intermediates. Pyridines would form from the reaction between amino groups and aldehyde, while the reaction between amino and keto groups results in the formation of pyrroles. Some amines remain free from reacting with other groups. ${ }^{33}$ These functionalities are later identified in the structure of NCDs.

Figure 1(a, b) shows the transmission electron microscopy (TEM) images of NCDs with spherical morphologies. The atomic force microscopy (AFM) images of the NCDs (Figure 1c, d) further prove that the sizes of those NCDs are uniformly distributed. The CDs are $\sim 2-8 \mathrm{~nm}$ in height, values obtained from cross-sectional topographic measurements, taken into account the broadening effect due to the finite size of the tip.

To analyse the structure of the carbon core, the output of XRD and Raman spectroscopy techniques were compared. The X-ray diffraction (XRD) pattern (Figure S2a) displays a broad 
peak centred at $21^{\circ}$, which has been demonstrated to be amorphous with turbostratic structure in our previous study. ${ }^{31}$ In theory, XRD involves X-rays interacting with electrons to reveal the reciprocal space of crystalline lattice by diffraction, which does not give sufficient structural information of packed carbon dots due to the less ordered structure. In this regard, Raman spectroscopy uses long wavelength radiation and interacts with atoms, molecules or ions, which can reveal the vibration frequencies of the system by scattering, providing information about the chemical environments. Hence here Raman spectroscopy was carried out for the surface characterisation of partially ordered carbon materials. ${ }^{34}$ Figure S2b shows the Raman spectra $(\lambda$ $=633 \mathrm{~nm}$ ) of the NCDs. Two peaks centred at $1382 \mathrm{~cm}^{-1}$ and $1574 \mathrm{~cm}^{-1}$ can be seen, representing the characteristic $\mathrm{D}$ and $\mathrm{G}$ bands for carbon materials, respectively, indicating a semi-crystalline structure of the NCDs. The spectra show a significant level of noise-to-signal ratio, due to the highly fluorescent background removal.

The X-ray photoelectron spectroscopy (XPS) spectra are shown in Figure 1(e, f, g). They reveal that the amine groups from chitosan are mentained on the surface of NCDs, and the carbon, oxygen, nitrogen contents have been calculated to be $75.8 \%, 28.2 \%$ and $5.8 \%$, respectively. Three types of nitrogen species can be found in the material, which are pyridinic $\mathrm{N}(26 \%)$, amine groups (64\%) and pyrrolic $\mathrm{N}(10 \%)$, existing both on the surface as functional groups and incorporated inside the core structure. It has been reported that different N-motifs show different charge transportation properties, which will be beneficial for the PEC properties. ${ }^{28}$ The Fourier transform infrared (FTIR) spectrum in Figure 1(i) also confirms the existence of amine groups in the NCDs, with $\mathrm{NH}_{2}$ bending at $1648 \mathrm{~cm}^{-1}$ and $\mathrm{N}-\mathrm{H}$ stretching at $1576 \mathrm{~cm}^{-1}$. The peaks between 1151 and $1484 \mathrm{~cm}^{-1}$ are assigned to $\mathrm{C}-\mathrm{NH}$ and $\mathrm{C}-\mathrm{N}=$ amide groups. ${ }^{35,36} \mathrm{~A}$ schematic profile representing the structure of NCDs is shown in Figure 1h. 
The optical properties of the NCDs are analyzed by UV-Vis absorption and photoluminescence. As shown in Figure S3a, the UV-Vis absorption spectrum of NCD solution exhibits strong, broad light absorption in the ultraviolet range, with an absorption peak at $270 \mathrm{~nm}$, which tails off in the visible region. The $270 \mathrm{~nm}$ absorption peak is due to the $\pi \rightarrow \pi^{*}$ transition, while the visible light absorption comes from $n \rightarrow \pi^{*}$ transition..$^{37,38}$ The visible light response of the synthesized NCDs is advantageous for use as a photosensitizer. ${ }^{14}$ In Figure S3b, excitation-dependent emission was observed in the blue-green light region depending on the excitation wavelength, indicating easy access to the electronic states $\left(n-\pi^{*}, \pi-\pi^{*}\right) .{ }^{39}$ These interesting optical properties grant the NCDs with potential applications in hybrid PEC design. Photoluminescence quantum yield $(\Phi)$ of NCDs was calculated to be $8.7 \%$ referenced by quinine sulphate (QS). ${ }^{40}$

Our previous work has shown that the NCDs derived from chitosan are capable of generating photocurrents under visible light irradiation, akin to the electronic structure of n-type semiconductor, and the excited states of carbon dots upon interaction with light govern the photoinduced activity. ${ }^{31}$ To investigate the nature of stable surface paramagnetic defects, EPR measurements were performed on NCD powder at room temperature in dark condition. In Figure S4, the sharp isotropic EPR signals centred at $\mathrm{g}_{\text {iso }}=2.0035$ is expected to come from the presence of carbon centred radical species present on the NCD surface, which could act as active sites for redox reactions.

The excited state photophysical properties of NCDs were investigated by mean of femtosecond transient absorption spectroscopy (fs-TAS) which reveals that upon $375 \mathrm{~nm}$ photoexcitation, NCDs gave rise to differential absorption signals that are spanning over the visible range from 450-750 nm on a ps timescale (Figure 1j). Features are centred near $500 \mathrm{~nm}$ and $625 \mathrm{~nm}$, similar to previously reported spectra of $\mathrm{CDs} .^{27,37}$ The features showed up at shorter and longer 
wavelengthes are possibly assigned to core and surface states of CDs, respectively. This behaviour is akin to that observed for graphitic carbon dots. ${ }^{27,41}$ The decay lifetime kinetics at $500 \mathrm{~nm}$ were fitted using a bi-exponential function into short (2.17 ps, 39\%) and long (138.97 ps, 61\%) lived components. The extracted excitons lifetimes have been found being longer than any other photosensitising materials reported to date. ${ }^{42,43}$ The comparison of the decay profile of NCDs with that of non-doped CDs in Figure 1k reveals that doping with $\mathrm{N}$ has largely prolonged the exciton lifetime, being beneficial for the PEC process. This might be a result of $\mathrm{N}$ doping reducing $\pi$ connections between $\mathrm{sp}^{2}$ domains, suppressing the interlayer non-radiative energy dissipation, ${ }^{21}$ and serve as electron donor to effectively scavenge holes to extend the lifetime of photogenerated electrons..$^{27}$ Here we have demonstrated for the first time clear evidence and explanation of the positive effect of $\mathrm{N}$ doping in carbon dots for the application as efficient photosensitizers. We have applied the prepared NCDs to $\mathrm{TiO}_{2}$, which is an ideal model semiconductor to study the effect of the NCDs in the recombination rate of the photogenerated charge carriers in a PEC system. Compared to inorganic semiconducting quantum dots, carbon dots consist of mostly $\mathrm{sp}^{2}$ carbon, which helps the formation of a charge-transfer complex with $\mathrm{TiO}_{2}$ and thus resulting in more efficient absorption and charge separation. ${ }^{44}$

The $\mathrm{TiO}_{2}$ thin film is fabricated by spin-coating a commercially available mesoporous titania paste onto fluorine-doped tin oxide (FTO) coated glass substrate. To gain insight into the morphology of the $\mathrm{TiO}_{2}$ film, we performed SEM top-view and cross-section imaging of the $\mathrm{NCDs} / \mathrm{TiO}_{2}$ film, with representative images portrayed in Figure S5. No major aggregation of the nanoparticles can be observed. The thickness of the film was measured to be $\sim 1 \mu \mathrm{m}$ (from the SEM cross-section), considered adequate to provide good charge carrier generation and collection ability. ${ }^{45}$ Brunauer-Emmett-Teller (BET) measurements showed that the $\mathrm{TiO}_{2}$ has a specific 
surface area of $110 \mathrm{~m}^{2} / \mathrm{g}$, higher than the commercial P25 $\left(49 \mathrm{~m}^{2} / \mathrm{g}\right)$. The mesoporosity, as seen from the SEM top view image guarantees sufficient light absorption and is also beneficial for anchoring the NCDs on its surface and inside the $\mathrm{TiO}_{2}$ films, providing more active sites for reactions. ${ }^{14}$

Figure $\mathbf{S 6}$ displays the $\mathrm{XRD}$ patterns of the $\mathrm{TiO}_{2}$ and $\mathrm{NCDs} / \mathrm{TiO}_{2}$ films. The dominant peak in both samples are assigned to the (101) facet of anatase phase, which is considered to be the most stable structure in anatase $\mathrm{TiO}_{2} \cdot{ }^{46}$ The diffraction patterns of $\mathrm{NCDs} / \mathrm{TiO}_{2}$ are in good match with that of the $\mathrm{TiO}_{2}$ which contains mostly anatase phase with small amount of rutile (JCPDS 01-0841286, 01-073-2224), indicating that the deposition of NCDs does not cause any obvious changes in $\mathrm{TiO}_{2}$ crystallinity. ${ }^{47}$ 

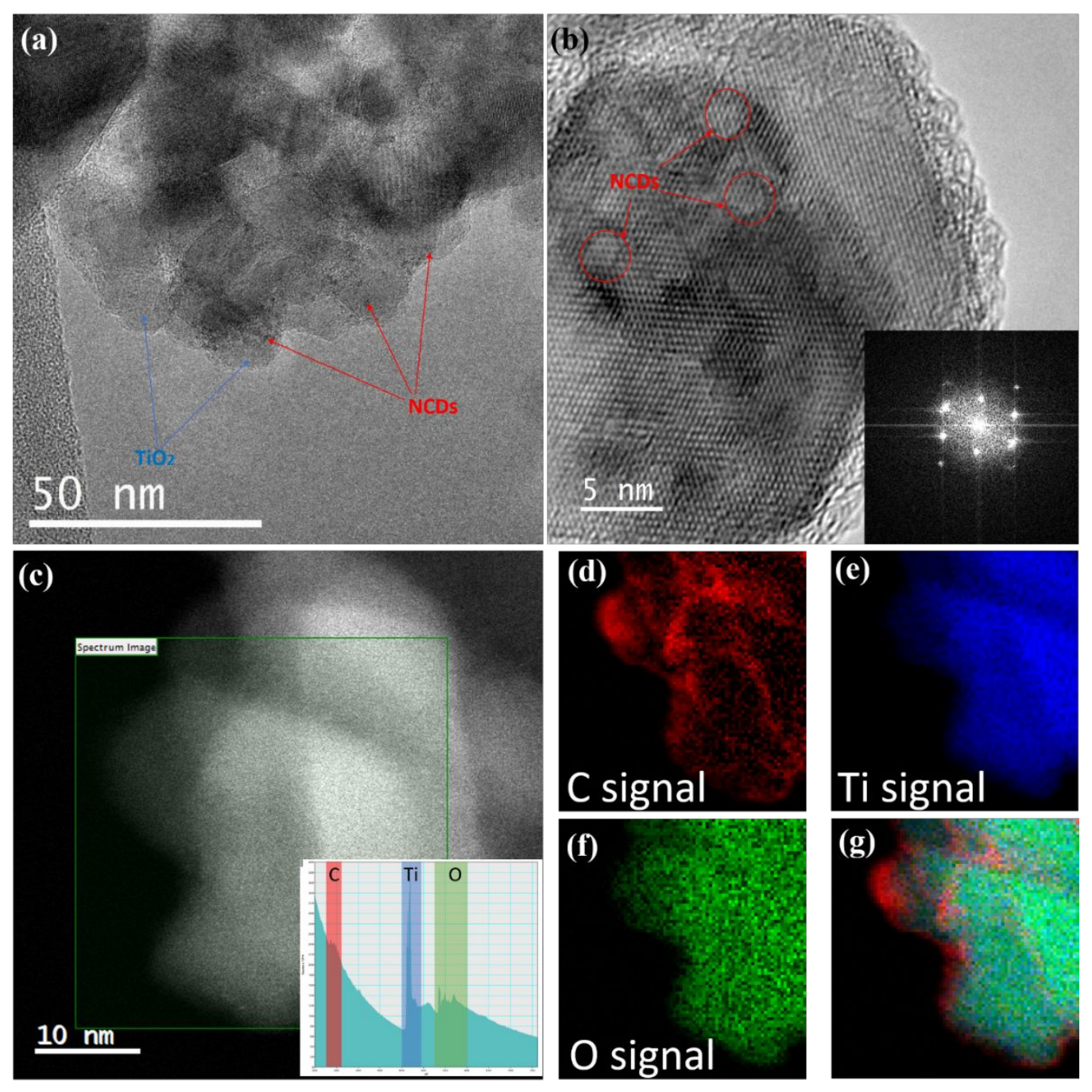

Figure 2 TEM (a) and HR-TEM (b) of $\mathrm{NCDs} / \mathrm{TiO}_{2}$ (insert is the FFT patterns); (c) HAADF image of $\mathrm{NCDs} / \mathrm{TiO}_{2}$ and corresponding EELS spectra (inserted). The single element maps derived from the spectra: (d) C signal, (e) Ti signal, (f) O signal and (g) colour mix (red: C, blue: Ti, green: O).

TEM and HR-TEM were used to investigate the morphologies of the $\mathrm{NCDs} / \mathrm{TiO}_{2}$ nanoparticles further. TEM image (Figure 2a) of the prepared $\mathrm{NCDs} / \mathrm{TiO}_{2}$ nanoparticles taken at lowmagnification shows some dark spots dispersed on the surface of the $\mathrm{TiO}_{2}$, revealing that the $\mathrm{NCDs}$ have been effectively deposited onto $\mathrm{TiO}_{2}$. In the HR-TEM images, the NCDs became less obvious, leaving only contract differences due to the small particle size and less crystallined nature 
of the NCDs compared to $\mathrm{TiO}_{2}$ nanoparticles, as determined by TEM and XRD (Figure 1 and S2). The observed lattice spacing of $0.35 \mathrm{~nm}$ for $\mathrm{TiO}_{2}$ nanoparticles correspond to the (101) plane of anatase $\mathrm{TiO}_{2}$, as can be seen from XRD patterns in Figure S6. To further resolve the presence of NCDs, high-angle annular dark-field image (HAADF) was taken on several $\mathrm{TiO}_{2}$ nanoparticles under high magnification. As seen in Figure 2c, NCDs are difficult to discern through the darkfield image due to the light element contrast. At the same area electron energy loss spectra (EELS) was scanned. It is known that EELS is better than EDS at detecting light elements due to the smaller energy window. Here we chose to look at $250-750 \mathrm{eV}$, which contains the characteristic spectra of carbon, nitrogen, titanium and oxygen, as illustrated in Figure $\mathbf{2 c}$ inserted. The spectra of $\mathrm{C}, \mathrm{Ti}$ and $\mathrm{O}$ are very distinctive, while no signal can be seen from N, probably due to the low nitrogen amount in the NCDs $(\mathrm{N} 5.8 \%)$ also loaded in small amounts on the $\mathrm{TiO}_{2}(\sim 2.4 \%$ calculated from the mass loss in Figure S7). The EELS maps of individual elements along with the colour mix are shown in Figure 2(d-g). The mapping of the $\mathrm{NCDs}$ on $\mathrm{TiO}_{2}$ infers the heterostructure formation, which may promote the charge separation within the hybrid system, corroborating the improved PEC activity. ${ }^{48}$ 
(a)

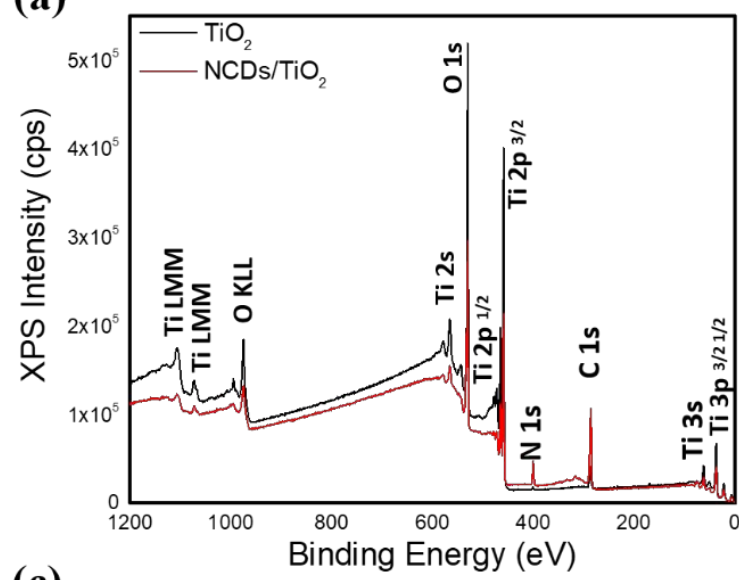

(c)

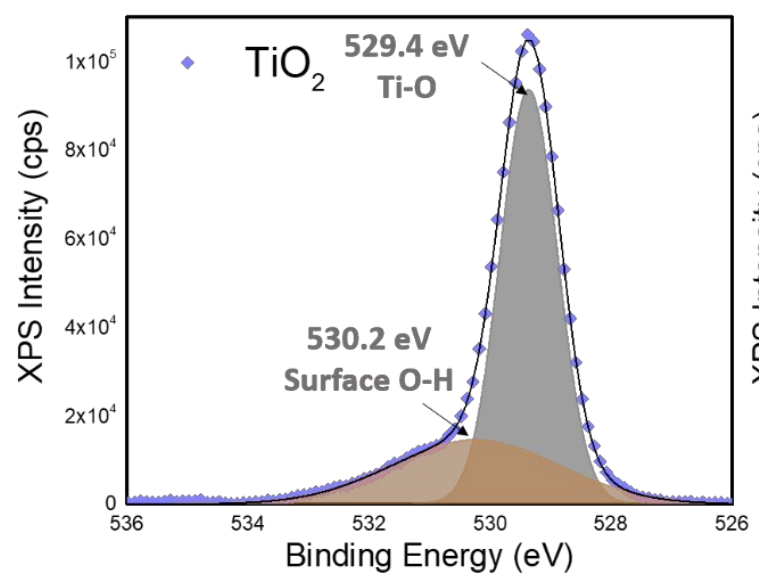

(e)

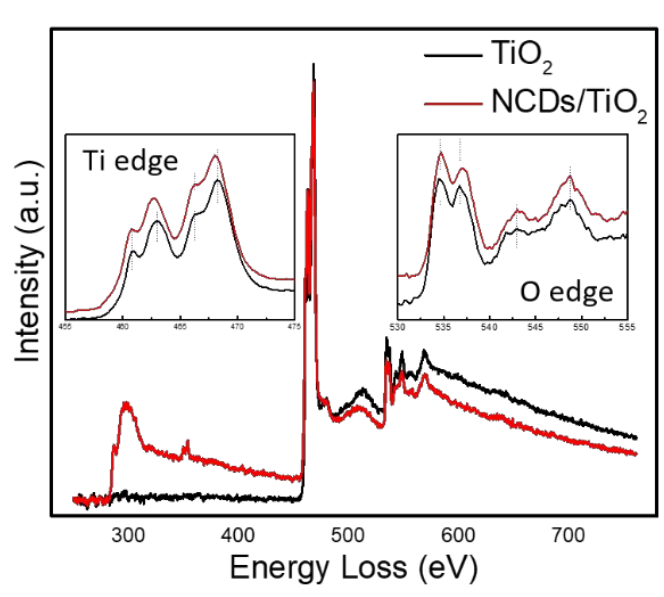

(b)

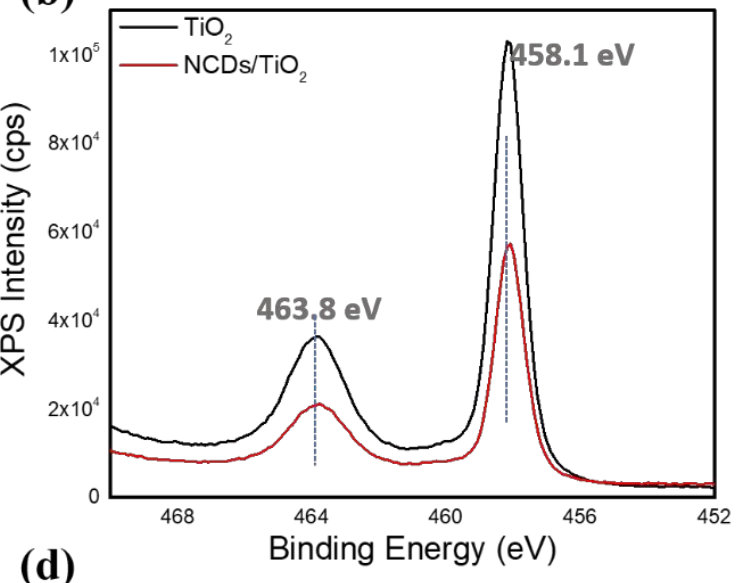

(d)

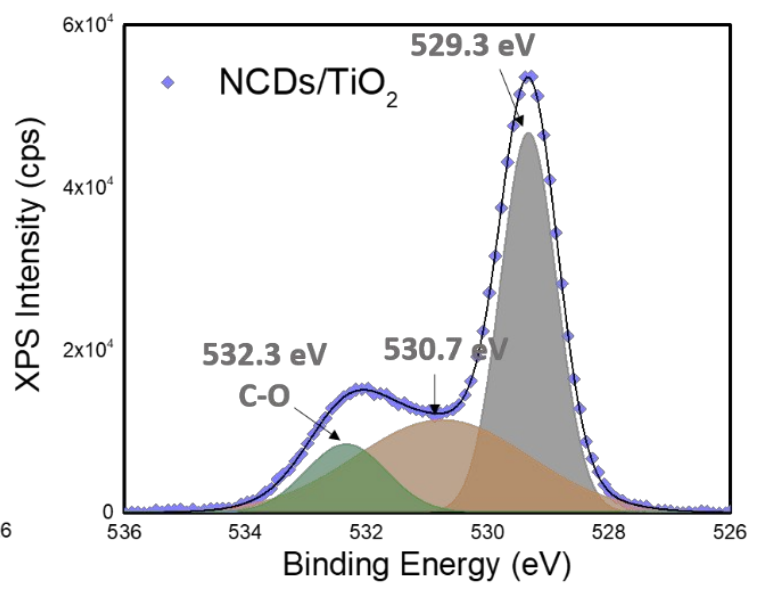

(f)

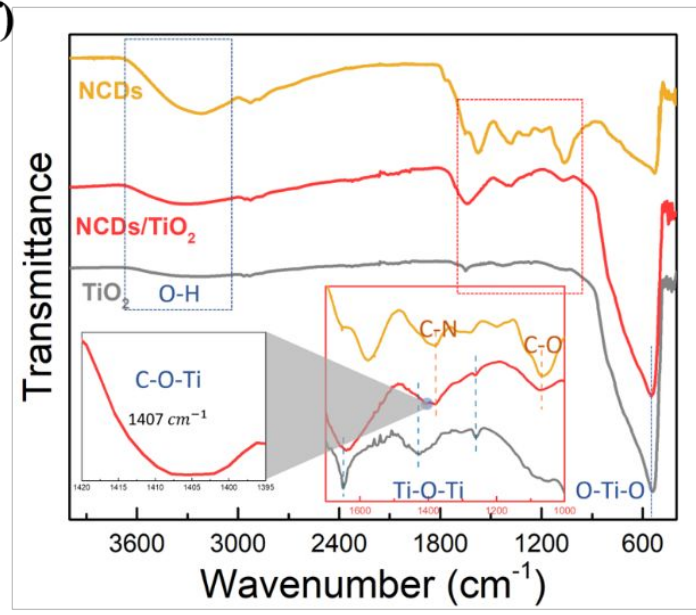

Figure 3 Comparison of XPS survey spectra (a) and Ti 2p high-resolution spectra (b) of the $\mathrm{TiO}_{2}$ and $\mathrm{NCDs} / \mathrm{TiO}_{2}$ films; $\mathrm{O}$ 1s spectra of (c) $\mathrm{TiO}_{2}$ and (d) $\mathrm{NCDs} / \mathrm{TiO}_{2}$. (e) EELS spectra of $\mathrm{TiO}_{2}$ (black) and $\mathrm{NCDs} / \mathrm{TiO}_{2}$ (red) and (f) FTIR signals. 
The chemical structure of the $\mathrm{NCDs} / \mathrm{TiO}_{2}$ was analysed by XPS. Compared to the pristine $\mathrm{TiO}_{2}$, the survey spectrum (Figure 3a) of $\mathrm{NCDs} / \mathrm{TiO}_{2}$ showed higher intensity in $\mathrm{C}$ and $\mathrm{N}$ peaks, which originates from the NCDs. The deconvoluted high-resolution signals of Ti 2 p (Figure $3 \mathbf{b}$ ) show no shift in the binding energy, suggesting that there is no disruption of the $\mathrm{TiO}_{2}$ structure after anchoring of the NCDs. The peaks at $458.1 \mathrm{eV}$ and $463.8 \mathrm{eV}$ are orginated from the pair of Ti $2 \mathrm{p}_{3 / 2}$ and $\mathrm{Ti} 2 \mathrm{p}_{1 / 2}$, respectively, assigned to the $\mathrm{Ti}^{4+}$ sp peaks of $\mathrm{TiO}_{2}$. Figure $3 \mathbf{c}$ shows the $\mathrm{O} 1 \mathrm{~s}$ spectra of $\mathrm{TiO}_{2}$, in which the peaks at $529.4 \mathrm{eV}$ and $530.2 \mathrm{eV}$ arise from Ti-O and surface O-H groups in $\mathrm{TiO}_{2}$, respectively. ${ }^{49}$ After depositing of NCDs, the surface O-H peak shifted towards higher binding energy, suggesting that the chemical environment has been changed due to the interaction between the $\mathrm{TiO}_{2}$ and NCDs and the formation of the Ti-O-C bond. ${ }^{11}$ The $\mathrm{O}$ 1s spectrum also showed a peak at $532.3 \mathrm{eV}$ corresponding to $\mathrm{C}-\mathrm{O}$ bonds, which is also present in the $\mathrm{O}$ 1s spectra of NCDs (Figure 1f). The energy shift can also be observed in high-resolution EELS spectra at Ti and $\mathrm{O}$ edges after depositing NCDs (Figure 3e), suggesting a chemical environment change around surface $\mathrm{Ti}$ and $\mathrm{O}$ atoms. ${ }^{50,51}$

The formation of $\mathrm{NCDs} / \mathrm{TiO}_{2}$ hybrid has been further confirmed by FTIR analysis. Figure 3f shows that the spectra of $\mathrm{NCDs} / \mathrm{TiO}_{2}$ display typical vibration of $\mathrm{O}-\mathrm{Ti}-\mathrm{O}$ at $550 \mathrm{~cm}^{-1}$, as well as C-N, C-O stretching at 1378 and $1067 \mathrm{~cm}^{-1}$, confirming the presence of NCDs in the hybrid sample. A new absorption peak arises between the Ti-O-Ti and C-N bond at $1407 \mathrm{~cm}^{-1}$, which is possible through the $\mathrm{C}-\mathrm{O}-\mathrm{Ti}$ bond formation. ${ }^{52}$ Based on the above results, it can be concluded that the NCDs are loaded on the $\mathrm{TiO}_{2}$ via chemical absorption. 
(a)

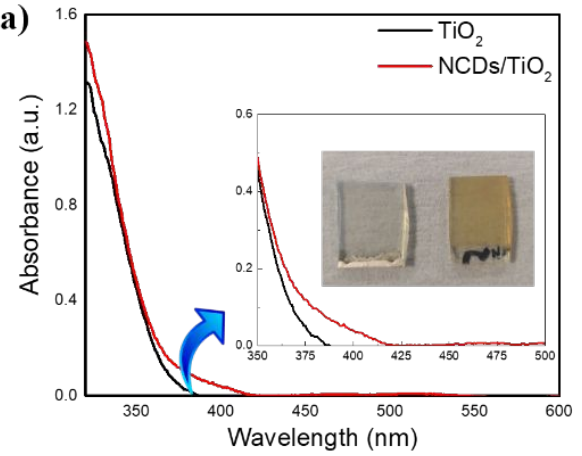

(c)

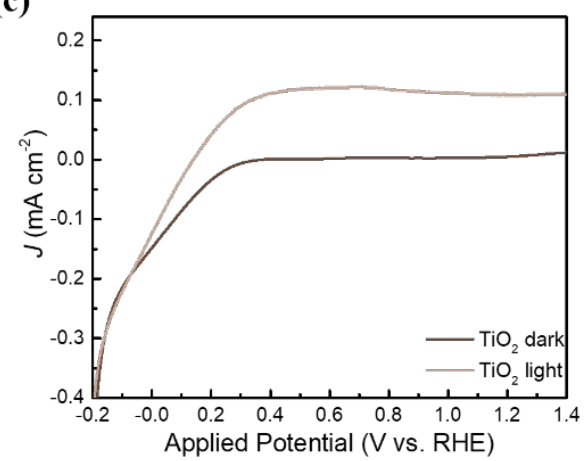

(e)

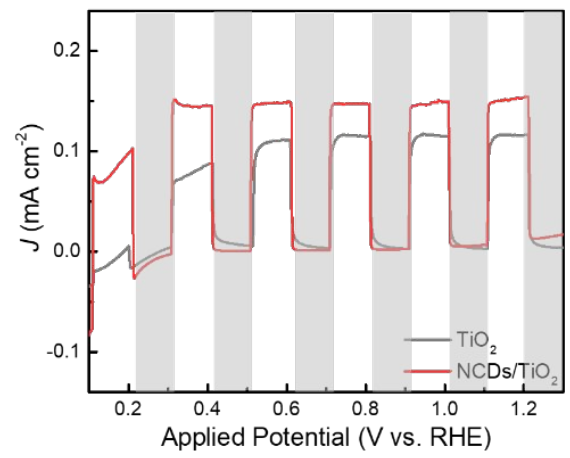

(g)

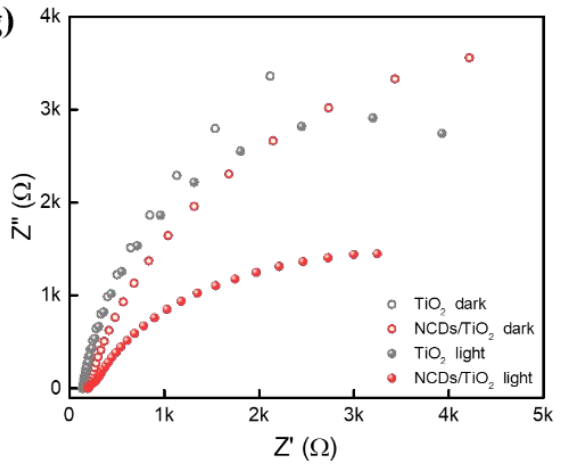

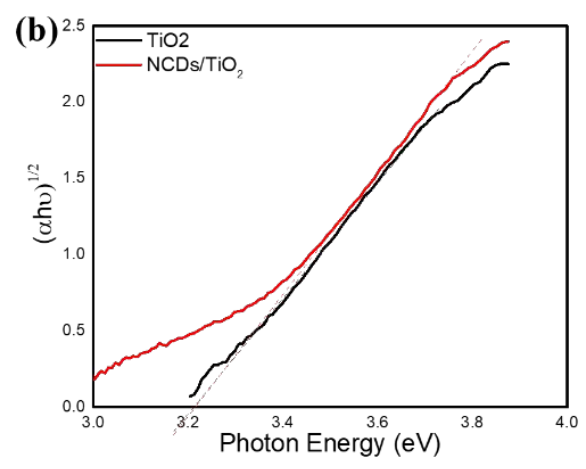

(d)

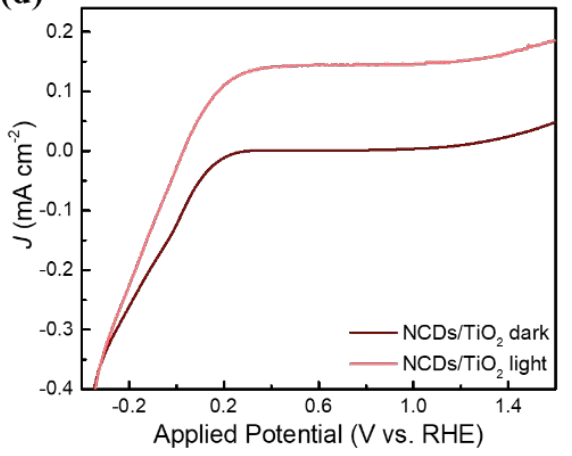

(f)
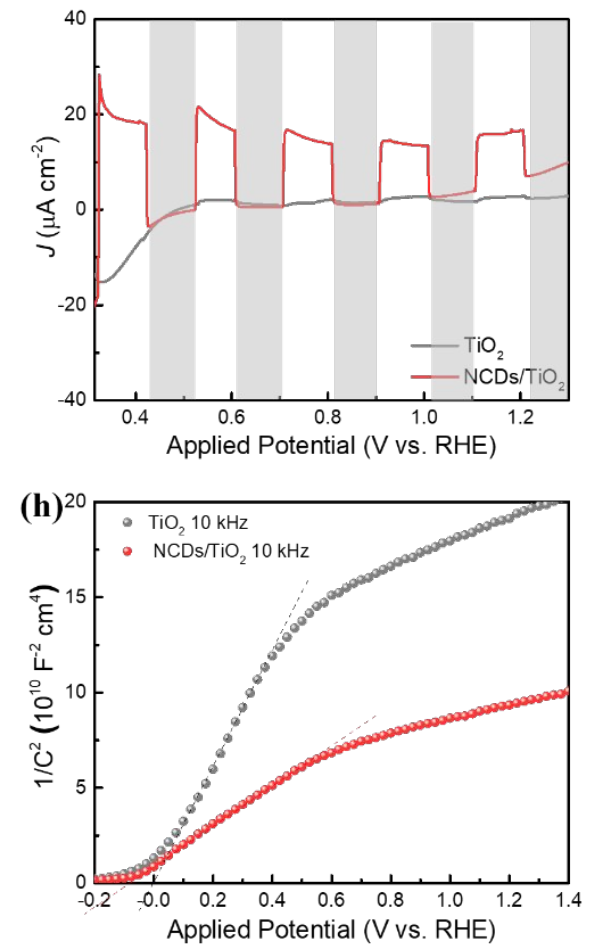

Figure 4 optoelectronic properties of $\mathrm{TiO}_{2}$ and $\mathrm{NCDs} / \mathrm{TiO}_{2}$ films: (a) UV-Vis absorption (inserted are the digital pictures of the films: left: $\mathrm{TiO}_{2}$, right: $\mathrm{NCDs} / \mathrm{TiO}_{2}$ ); (b) tauc plot of $\mathrm{TiO}_{2}$ and 
$\mathrm{NCDs} / \mathrm{TiO}_{2}$ with indirect band gap; LSV curves of (c) $\mathrm{TiO}_{2}$ and (d) $\mathrm{NCDs} / \mathrm{TiO}_{2}$ under dark and light conditions; the chopped photocurrent response of the two samples under (e) full spectrum and (f) visible light $(\lambda>420 \mathrm{~nm}$ ) illumination; (g) EIS Nyquist plots under simulated solar light illumination $\left(100 \mathrm{kHz}-0.1 \mathrm{~Hz}, 0.3 \mathrm{~V}\right.$ vs. RHE, $\left.100 \mathrm{~mW} \mathrm{~cm}^{-2}\right)$ and (h) Mott-Schottky plots with $10 \mathrm{kHz}$ frequency under dark condition at equilibrium.

Light absorption is one of the essential factors determining the PEC performance of electrode materials. UV-Vis-NIR spectroscopy is employed to characterise the optical properties of the $\mathrm{TiO}_{2}$ films and their respective NCD hybrids. As shown in Figure 4a, pure $\mathrm{TiO}_{2}$ show no absorption above $385 \mathrm{~nm}$ owing to the intrinsic wide band gap of anatase $\mathrm{TiO}_{2}(3.2 \mathrm{eV})$. Compared to the pristine $\mathrm{TiO}_{2}$ film, the NCD decorated films show enhanced visible light absorption tails up to 425 $\mathrm{nm}$ for $\mathrm{NCDs} / \mathrm{TiO}_{2}$. Therefore, the presence of NCDs plays a critical role in boosting the visible light absorption of the composites, which is important for visible-light-driven photoelectrocatalytic activity. No bandgap narrowing can be observed from the Tauc plot (Figure 4b), indicating that the NCDs are only present on the surface without disrupting the crystalline structure of $\mathrm{TiO}_{2}$, in line with the STEM and XRD results.

PEC measurements were performed on the aforementioned $\mathrm{TiO}_{2}$ films to investigate the photoinduced charge transfer behaviour. Figure 4c-f show the linear sweep voltammetry (LSV) of the photoelectrodes under simulated solar light irradiation (electrolyte: $0.2 \mathrm{M} \mathrm{Na} \mathrm{SO}_{4}$ aqueous solution; scan rate: $5 \mathrm{mV} / \mathrm{s}$ ). Clearly, the $\mathrm{NCDs} / \mathrm{TiO}_{2}$ photoanode showed enhanced photoresponse compared to pure $\mathrm{TiO}_{2}$; the $\mathrm{NCDs} / \mathrm{TiO}_{2}$ displays a saturation photocurrent of $0.15 \mathrm{~mA}$ $\mathrm{cm}^{-2}$ at $0.3 \mathrm{~V}$ vs RHE, approximately two times higher than that of the pristine $\mathrm{TiO}_{2}\left(0.08 \mathrm{~mA} \mathrm{~cm}^{-2}\right)$ under the same conditions. This may be the effect of the formation of heterojunctions at the $\mathrm{NCDs} / \mathrm{TiO}_{2}$ interface, which can effectively separate the photo-induced charge carriers. The 
expected PEC results under visible light $(\lambda>420 \mathrm{~nm})$ further depict the enhanced charge separation of $\mathrm{TiO}_{2}$ by hybridising $\mathrm{NCDs}$. While $\mathrm{TiO}_{2}$ electrode showed no obvious photo-response in this region, the $\mathrm{NCDs} / \mathrm{TiO}_{2}$ generated photocurrent of $17 \mu \mathrm{A} \mathrm{cm}{ }^{-2}$, owing to the slightly enhanced visible absorption of NCDs. Consequently, based on the above results, the photosensitization effect of NCDs on the photocurrent generation of $\mathrm{NCDs} / \mathrm{TiO}_{2}$ heterostructures was unambiguously ascertained under both simulated solar and visible light illuminations.

The distribution of the photocurrent between UV and visible light is given in Figure S8. Nearly half of the enhanced photo-carrier generation of $\mathrm{NCDs} / \mathrm{TiO}_{2}$ is attributed to the higher visible light absorption, due to the photosensitization ability of NCDs. The rest of the improved photocurrent may arise from a more efficient charge separation and transportation because of the formed heterojunction between $\mathrm{TiO}_{2}$ and NCDs. ${ }^{29,53}$ Stability test was performed on the $\mathrm{NCDs} / \mathrm{TiO}_{2}$ photoelectrode. As seen from Figure S9, $\mathrm{NCDs} / \mathrm{TiO}_{2}$ exhibit a current density decrease in the first $2000 \mathrm{~s}$, but with time proceeds, the electrode became more stable, with less than $25 \%$ current density drop. Future work is needed to improve the stability of this hybridized material.

The electron-hole pair separation efficiency were further analysed with EIS measurements. In the Nyquist plots, the charge transfer process at the electrode/electrolyte interface is represented by the diameter of the semicircle at low frequency; a smaller diameter indicates a lower charge transfer resistance. Figure $\mathbf{4 g}$ shows the Nyquist plots of the $\mathrm{TiO}_{2}$ and $\mathrm{NCDs} / \mathrm{TiO}_{2}$ photoanodes from $100 \mathrm{kHz}$ to $0.1 \mathrm{~Hz}$ under simulated solar light illumination (0.3V vs RHE). The prepared $\mathrm{NCDs} / \mathrm{TiO}_{2}$ show a smaller semi-circular diameter compare to $\mathrm{TiO}_{2}$ under light illumination, revealing that the $\mathrm{NCDs} / \mathrm{TiO}_{2}$ electrode possesses less photo-induced charge transfer resistance in the interface of electrode and electrolyte, highlighting the key benefit of NCDs in improving charge separation efficiency and enhancing photoelectrochemical activity. Compare with the EIS 
performed under dark conditions, we can tell that the charge transfer resistance of $\mathrm{NCDs} / \mathrm{TiO}_{2}$ electrode decreased faster by light illumination compared with pristine $\mathrm{TiO}_{2}$. This proves that NCDs provided photosensitised electrons to $\mathrm{TiO}_{2}$ and separated the electron-hole pairs more efficiently, thereby decreasing the impedance under light. ${ }^{54}$ Additionally, the Mott-Schottky (MS) measured at $10 \mathrm{kHz}$ reveals a higher carrier density after NCDs deposition (Figure 4h) from the smaller slope of $\mathrm{NCDs} / \mathrm{TiO}_{2}$ curve..$^{50,55}$ To minimise the effect of surface state capacitance and the double-layer capacitance at the electrode/electrolyte interface, the frequency of the M-S measurements was chosen to be fast enough to limit the effective filling and unfilling of the electrodes' surface state, as well as restrain the builiding up of double layer capacitance. On that note, even though this analysis is derived from an ideal planar electrode model, the calculation of carrier density for a relative comparison is still reasonable. ${ }^{56}$ Measurements at different frequency $(1 \mathrm{kHz}$ and $3 \mathrm{kHz})$ can be found in Figure S10. The carrier density $\left(\mathrm{N}_{\mathrm{D}}\right)$ can be estimated by the equation:

$$
\frac{1}{C^{2}}=\frac{2}{\varepsilon \varepsilon_{0} A^{2} e N_{D}}\left(V-V_{f b}-\frac{k_{B} T}{e}\right)
$$

Where $e=1.6 \times 10^{-19} C, \varepsilon_{0}=8.86 \times 10^{-12} \mathrm{Fm}^{-1}, \varepsilon=55$ for $(101)$ facet anatase $\mathrm{TiO}_{2}$ with a small amount of rutile, 55,57 and $\mathrm{C}$ is the capacitance. By using these values, we obtain the average donor densities of $8.44 \times 10^{18} \mathrm{~cm}^{-3}$ and $2.67 \times 10^{19} \mathrm{~cm}^{-3}$ for $\mathrm{TiO}_{2}$ and $\mathrm{NCDs} / \mathrm{TiO}_{2}$ electrodes, respectively. The extrapolation of the M-S plot to the $\mathrm{x}$ - intercept gives flat potential of the electrode, in which the NCDs modified $\mathrm{TiO}_{2}$ show a slightly negative potential than that of $\mathrm{TiO}_{2}$, by $0.1 \mathrm{~V}$, which may due to the hybridised band structure of $\mathrm{NCDs}$ and $\mathrm{TiO}_{2}$ and favours the migration of photoinduced electrons from $\mathrm{NCDs}$ to $\mathrm{TiO}_{2} \cdot{ }^{39}$ 

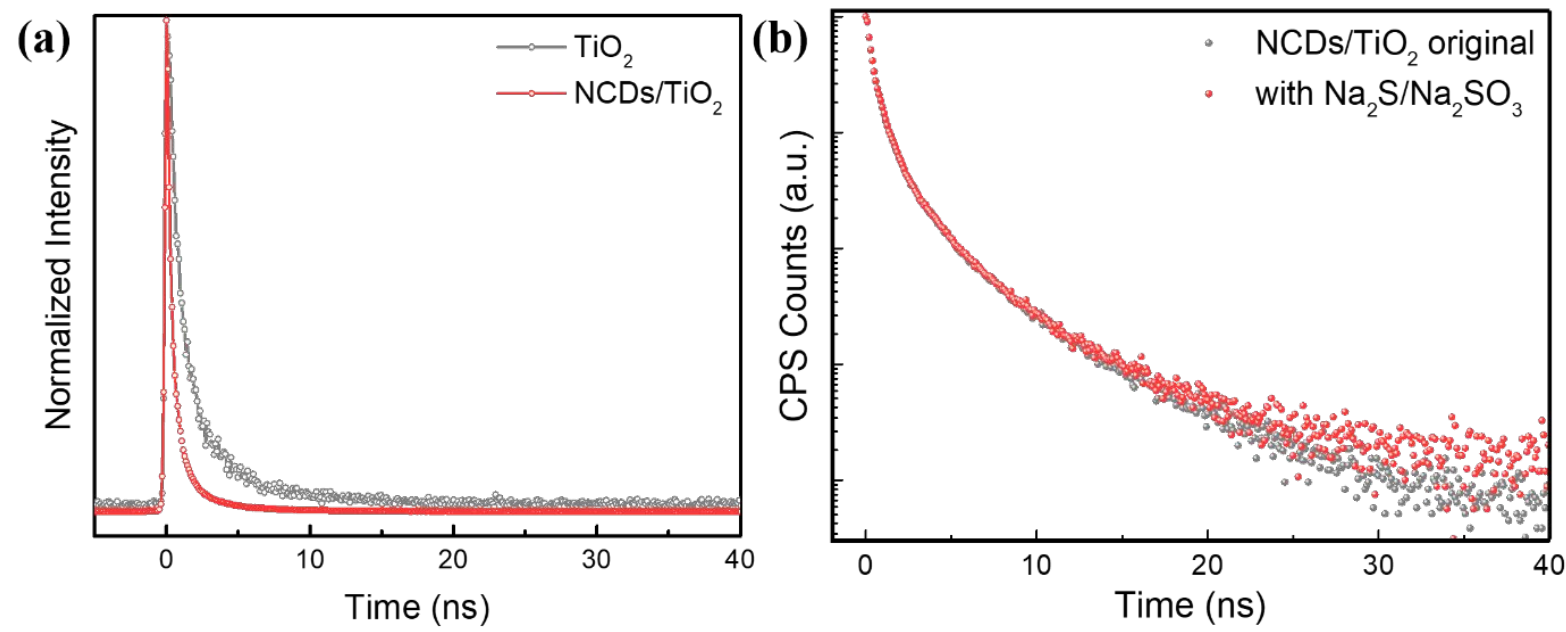

Figure 5 (a) TCSPC decay profile of $\mathrm{TiO}_{2}$ (grey) and $\mathrm{NCDs} / \mathrm{TiO}_{2}$ (red); (b) decay profiles of $\mathrm{NCDs} / \mathrm{TiO}_{2}$ with (red) and without (grey)the presence of hole scavenger $\mathrm{Na}_{2} \mathrm{~S}_{2} \mathrm{Na}_{2} \mathrm{SO}_{3}$. The excitation wavelength for all the experiments is $405 \mathrm{~nm}$, and the emission is recorded at $520 \mathrm{~nm}$.

To further study and gain greater insight into the charge transfer properties in $\mathrm{NCDs} / \mathrm{TiO}_{2}$ heterostructure, Time-correlated Single Photon Counting measurement was performed on pristine $\mathrm{TiO}_{2}$ and NCDs decorated sample. From Figure 5a we can observe a faster photoluminescence (PL) decay after depositing NCDs, which clearly indicate the existence of charge transfer between NCDs and $\mathrm{TiO}_{2}$, suppressing the radiative charge recombination in $\mathrm{TiO}_{2} \cdot{ }^{43}$ The PL quenching of the samples were tested in-situ in an electrolyte with the presence of hole scavengers $\left(\mathrm{Na}_{2} \mathrm{~S} / \mathrm{Na}_{2} \mathrm{SO}_{3}\right)$. It is advised that the presence of hole scavengers can effectively react with photogenerated holes and enrich the electrons in a photocatalyst system, ${ }^{58}$ facilitate charge separation and prevent electron-hole recombination, leading to a lower PL and shorter PL lifetime. Comparing the decay profiles of $\mathrm{NCDs} / \mathrm{TiO}_{2}$ with/without hole scavengers in Figure $\mathbf{5 b}$, it can be seen that the PL lifetime remained almost identical, suggesting a negligible PL quenching process. In comparison, the PL lifetime of $\mathrm{TiO}_{2}$ has dramatically decreased from 3.14 ns to $1.75 \mathrm{~ns}$ after adding hole scavengers (Figure S11). This is probably due to the efficient charge separation in the 
$\mathrm{NCDs} / \mathrm{TiO}_{2}$ system, with photogenerated electrons transferred to $\mathrm{TiO}_{2}$ and holes transported to the surface of NCDs. ${ }^{59,60}$

Combined ultraviolet photoemission spectroscopy (UPS) and photoelectron spectroscopy in air (PESA) techniques provide insights into the electronic structure and energy band positions of the $\mathrm{NCDs} / \mathrm{TiO}_{2}$ materials. The value of ionisation potential of NCD powders from PESA in Figure S12a was determined to be $5.5 \mathrm{eV} \pm 0.02 \mathrm{eV}$, corresponding to the energy of the highest occupied electronic state $(\mathrm{HOMO})$ of NCDs. The Fermi level of NCDs $\left(E_{f 1}\right)$ was probed directly by Kelvin probe and was determined to be $-4.3 \mathrm{eV}$. The UV/Vis absorption spectrum of NCDs in Figure S2a suggests a relatively large energy gap of $3.5 \mathrm{eV}$, leaving the lowest unoccupied electronic state (LUMO) at $-2 \mathrm{eV}$. However, the excitation-dependent PL of NCDs (Figure S2b) indicates individual energy states of NCDs, which allows energy transitions extending up to $500 \mathrm{~nm}(2.48$ $\mathrm{eV}) .{ }^{31}$ The valence band edge and Fermi level $\left(E_{f 2}\right)$ of $\mathrm{TiO}_{2}$ from UPS are $-7.65 \mathrm{eV}$ and $-5.22 \mathrm{eV}$, respectively (Figure S12b), similar to the reported band position of anatase phase $\mathrm{TiO}_{2} \cdot{ }^{61,62} \mathrm{The}$ band gap (Eg) was calculated to be $3.21 \mathrm{eV}$ from Tauc plot (Figure 4b), from which according to $\mathrm{Eg}=\mathrm{E}_{\mathrm{C}}-\mathrm{E}_{\mathrm{V}}$, the conduction band $(\mathrm{CB})$ edge is estimated to be $-4.44 \mathrm{eV}$, above the $\mathrm{H}^{+} / \mathrm{H}_{2}$ reduction potential. As to the $\mathrm{NCDs} / \mathrm{TiO}_{2}$, the measured Fermi level $\left(E_{f 3}\right)$ is $-5.16 \mathrm{eV}$ by UPS, in between that of NCDs and $\mathrm{TiO}_{2}$, consistent with the observation in the PEC Mott-Schottky measurements mentioned previously. A continuous distribution of valence band states is observed up to $\sim 3.6 \mathrm{eV}$ in UPS concerning the Fermi level, indicating there are mid-states existing within the bandgap of the nanocomposite. These states are likely formed at the $\mathrm{NCDs} / \mathrm{TiO}_{2}$ interface and will promote hole transport from the valence band of $\mathrm{TiO}_{2}$ to the $\mathrm{HOMO}$ band of $\mathrm{NCDs} .^{63}$ Moreover, the ionization energy of NCDs at $5.5 \mathrm{eV}$, much smaller than the energy for $\mathrm{TiO}_{2}(7.65$ $\mathrm{eV}$ ), clear suggests a transfer of holes from $\mathrm{TiO}_{2}$ to $\mathrm{NCDs} .{ }^{63}$ To the best of our knowledge this is 
the first report that directly probes the band positions of carbon dots- $\mathrm{TiO}_{2}$ photoelectrode in a $\mathrm{PEC}$ system for understanding the energy transfer mechanism.

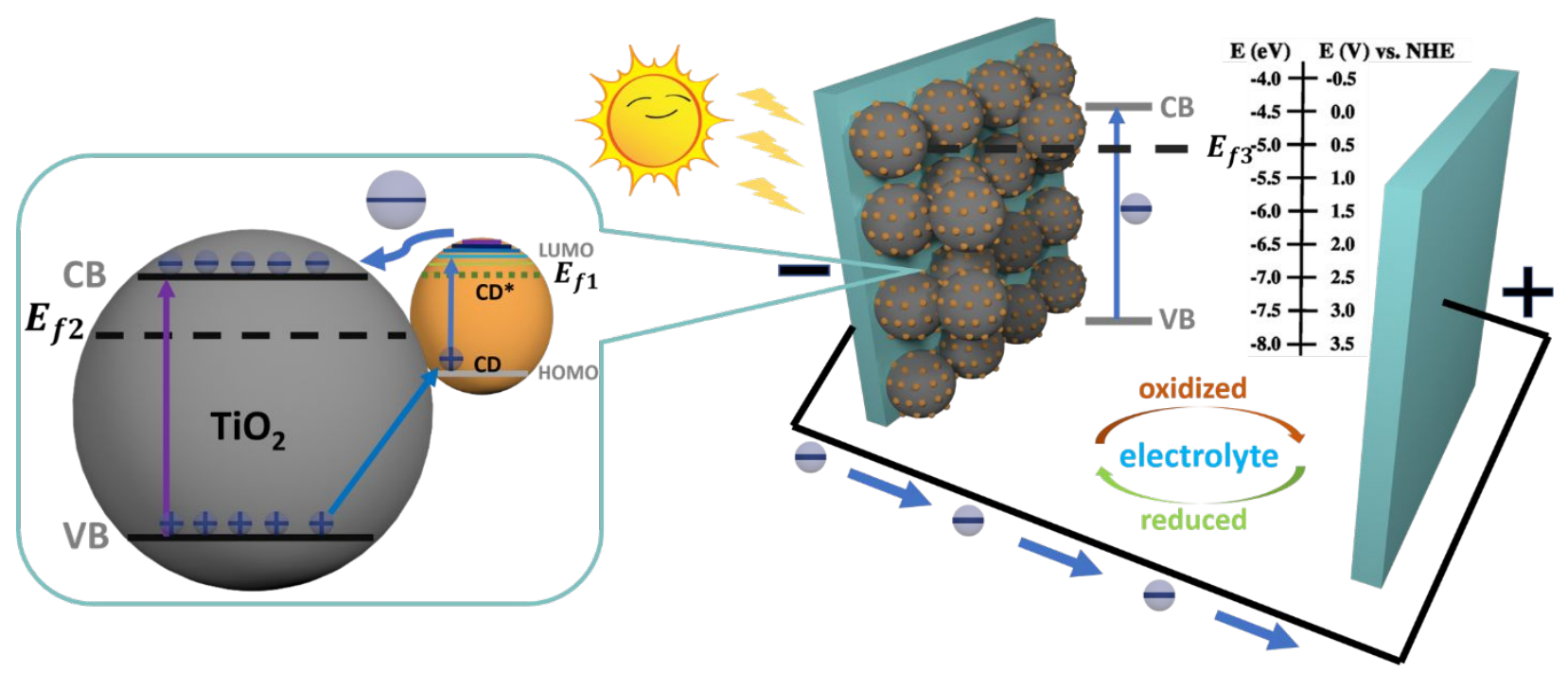

Figure 6 Proposed formation of the heterostructure with band alignments and charge transfer at the surface of $\mathrm{TiO}_{2}$ and NCDs under light irradiation.

Based on the above results, a schematic diagram of the PEC mechanism is depicted in Figure 6. Under full spectrum irradiation, the electrons on the HOMO of NCDs and valence band (VB) of $\mathrm{TiO}_{2}$ can be effectively excited to the LUMO/CB, respectively. The electrons from the LUMO band of NCDs can then quickly transfer to the $\mathrm{CB}$ of the $\mathrm{TiO}_{2}$ due to its deeper energy level. The holes left in the $\mathrm{VB}$ of $\mathrm{TiO}_{2}$ then transfer to the $\mathrm{NCDs}$, where it can react with the electrolyte for oxidation reactions. The accumulated electrons in $\mathrm{TiO}_{2}$ would then go into the external circuit to the counter electrode where reduction reactions take place, resulting in a higher measured photocurrent. While under visible light irradiation, the higher photoactivity is induced by obtaining a new absorption band through interfacial charge transfer. ${ }^{44}$ Electrons in NCDs were excited from HOMO band on to LUMO band, where they are effectively transferred through TiO2 into the circuit under positive bias, resulted in a higher photocurrent response. 
Our work has therefore shown that in this hybrid system the energy levels are arranged such that, a photon excites an electron-hole pair on the NCDs with a subsequent electron transfer to the $\mathrm{TiO}_{2}$, which would then be transferred to counter electrode. This leaves a hole in the valence band of the $\mathrm{NCDs}$ residing at $-5.5 \mathrm{eV}$ which provides a site for electron transfer from $\mathrm{OH}^{-}$, which is the electron donor (D) in the electrolyte solution. The conversion of $\mathrm{D}^{+}$from $\mathrm{D}$ with $\mathrm{NCDs} / \mathrm{TiO}_{2}$ as photocatalysts under illumination produces the photocurrent, completing the PEC circuit.

\section{Conclusions}

In summary, a facile solvothermal method was employed to synthesise nanoscale NCDs with good optical and PEC response in the UV-visible range. This type of carbon dots can be applied as a photosensitizer for improving the $\mathrm{PEC}$ activity of $\mathrm{TiO}_{2}$ and used as a model system to understand the fundamental mechanism of sensitisation using $\mathrm{NCDs}$. The obtained $\mathrm{NCDs} / \mathrm{TiO}_{2}$ electrode exhibits a higher photocurrent compared to the pristine $\mathrm{TiO}_{2}$, with an even greater enhancement under visible light illumination. A variety of complementary techniques such as HRSTEM, EELS, UV-Vis absorption, EIS, M-S, TCSPC and UPS were performed to investigate the optoelectronic properties, photo-induced charge transfer and band structure of the hybrid. The results reveal that the improved $\mathrm{PEC}$ activity for the $\mathrm{NCDs} / \mathrm{TiO}_{2}$ arises from the synergistic effect of NCDs combined with $\mathrm{TiO}_{2}$, which expand the light response into visible range as well as form type II heterojunction at the interface with well-resolved band postion probing which have been reported for the first time. We show here the charge transfer process between $\mathrm{NCDs}$ and $\mathrm{TiO}_{2}$, with in-depth analysis of the energy transitions to develop a comprehensive fundamental understanding on the favoured role of NCDs in the photoelectrocatalytic reactions. The importance of combining structural, photophysical and electrochemical assays on systematically improve the charge transfer process between carbon dots and their catalyst counterparts is also addressed here. 
Future work will focus on tuning the carbon dots properties and optimising the hybridisation with other photoelectrocatalytic systems or z-schemes for enhanced photocatalytic performances.

\section{ASSOCIATED CONTENT}

\section{Supporting Information}

The supporting Information is available free of charge on the ACS Publications website.

More characterizations on $\mathrm{NCDs} / \mathrm{TiO}_{2}$ 's morphology and chemical/physical properties. (PDF)

\section{AUTHOR INFORMATION}

\section{Corresponding Author}

*E-mail: m.titirici@imperial.ac.uk

\section{Author Contributions}

The manuscript was written through contributions of all authors. All authors have given approval to the final version of the manuscript. HL produced the $\mathrm{NCDs} / \mathrm{TiO}_{2}$ materials and performed all the basic characteristic techniques; SD helped with the TAS and TCSPC measurements; MD, JSK measured the fermi level while MAS, PS and OF helped with UPS and PESA analysis; HL, QG, YF, ABJ, XW and MMT co-wrote the paper. All authors have contributed to revise the manuscript.

\section{Notes}

The authors declare no competing financial interest.

\section{ACKNOWLEDGMENT}

HL and QG thanks the Chinese government for the award of CSC scholarships, and Dr Enrico Salvadori for the EPR measurement. SD is grateful for financial support by Edinburgh Instruments. This work is part-funded by the European Regional Development Fund through the Welsh Government. We thank the Diamond Light Source for access and support in the use of the electron 
Physical Science Imaging Centre (Instrument E01 proposal MG22447) that contributed to the results presented here. PS acknowledges financial support from the Agence Nationale de la Recherche through the Labex projects CSC (ANR-10-LABX-0026 CSC) within the Investissement d'avenir program (ANR-10-120 IDEX-0002-02), by the International Center for Frontier Research in Chemistry (icFRC). OF acknowledges support from the Royal Society through a University Research Fellowship (UF140372). XW thanks the National Natural Science Foundation of China (21861130353).

\section{REFERENCES}

(1) Fujishima, A., \& Honda, K. Electrochemical Photolysis of Water One and TwoDimensional Structure of Poly ( L-Alanine ) Shown by Specific Heat Measurements at Low. Nature 1972, 238, 37-38.

(2) Zhao, L.; Chen, X.; Wang, X.; Zhang, Y.; Wei, W.; Sun, Y.; Antonietti, M.; Titirici, M. M. One-Step Solvothermal Synthesis of a Carbon @TiO2 Dyade Structure Effectively Promoting Visible-Light Photocatalysis. Adv. Mater. 2010, 22 (30), 3317-3321.

(3) Yoo, I. han; Kalanur, S. S.; Seo, H. A Nanoscale p-n Junction Photoelectrode Consisting of an NiO x Layer on a TiO 2 /CdS Nanorod Core-Shell Structure for Highly Efficient Solar Water Splitting. Appl. Catal. B Environ. 2019, 250 (February), 200-212.

(4) Tada, H.; Mitsui, T.; Kiyonaga, T.; Akita, T.; Tanaka, K. All-Solid-State Z-Scheme in CdSAu-TiO2 Three-Component Nanojunction System. Nat. Mater. 2006, 5 (10), 782-786.

(5) Zhao, H.; Hu, Z.; Liu, J.; Li, Y.; Wu, M.; Van Tendeloo, G.; Su, B. L. Blue-Edge Slow Photons Promoting Visible-Light Hydrogen Production on Gradient Ternary 3DOM TiO2Au-CdS Photonic Crystals. Nano Energy 2018, 47 (December 2017), 266-274. 
(6) Sant, P. A.; Kamat, P. V. Interparticle Electron Transfer between Size-Quantized CdS and TiO2 Semiconductor Nanoclusters. Phys. Chem. Chem. Phys. 2002, 4 (2), 198-203.

(7) Lee, Y.-L.; Chi, C.-F.; Liau, S.-Y. CdS/CdSe Co-Sensitized TiO2 Photoelectrode for Efficient Hydrogen Generation in a Photoelectrochemical Cell. Chem. Mater. 2010, 22 (3), $922-927$.

(8) Zhang, F.; Zhang, C.-L.; Wang, W.-N.; Cong, H.-P.; Qian, H.-S. Titanium Dioxide/Upconversion Nanoparticles/Cadmium Sulfide Nanofibers Enable Enhanced FullSpectrum Absorption for Superior Solar Light Driven Photocatalysis. ChemSusChem 2016, 9 (12), 1449-1454.

(9) Xiong, Z.; Luo, Y.; Zhao, Y.; Zhang, J.; Zheng, C.; Wu, J. C. S. Synthesis, Characterization and Enhanced Photocatalytic CO2 Reduction Activity of Graphene Supported TiO2 Nanocrystals with Coexposed $\{001\}$ and $\{101\}$ Facets. Phys. Chem. Chem. Phys. 2016, 18 (19), 13186-13195.

(10) Lu, Y.; Cheng, X.; Tian, G.; Zhao, H.; He, L.; Hu, J.; Wu, S. M.; Dong, Y.; Chang, G. G.; Lenaerts, S.; Siffert, S.; Van Tendeloo, G.; Li, Z. F.; Xu, L. L.; Yang, X. Y.; Su, B. L. Hierarchical CdS/m-TiO2/G Ternary Photocatalyst for Highly Active Visible LightInduced Hydrogen Production from Water Splitting with High Stability. Nano Energy 2018, 47 (September 2017), 8-17.

(11) Yu, H.; Zhao, Y.; Zhou, C.; Shang, L.; Peng, Y.; Cao, Y.; Wu, L.-Z.; Tung, C.-H.; Zhang, T. Carbon Quantum Dots/TiO2 Composites for Efficient Photocatalytic Hydrogen Evolution. J. Mater. Chem. A 2014, 2 (10), 3344. 
(12) Tian, J.; Leng, Y.; Zhao, Z.; Xia, Y.; Sang, Y.; Hao, P.; Zhan, J.; Li, M.; Liu, H. Carbon Quantum Dots/Hydrogenated TiO2 Nanobelt Heterostructures and Their Broad Spectrum Photocatalytic Properties under UV, Visible, and near-Infrared Irradiation. Nano Energy 2015, 11, 419-427.

(13) Chen, P.; Wang, F.; Chen, Z. F.; Zhang, Q.; Su, Y.; Shen, L.; Yao, K.; Liu, Y.; Cai, Z.; Lv, W.; Liu, G. Study on the Photocatalytic Mechanism and Detoxicity of Gemfibrozil by a Sunlight-Driven TiO2/Carbon Dots Photocatalyst: The Significant Roles of Reactive Oxygen Species. Appl. Catal. B Environ. 2017, 204, 250-259.

(14) Wang, Q.; Huang, J.; Sun, H.; Zhang, K.-Q.; Lai, Y. Uniform Carbon Dots@TiO2 Nanotube Arrays with Full Spectrum Wavelength Light Activation for Efficient Dye Degradation and Overall Water Splitting. Nanoscale 2017, 9, 16046-16058.

(15) Liang, Z.; Hou, H.; Fang, Z.; Gao, F.; Wang, L.; Chen, D.; Yang, W. Hydrogenated TiO2 Nanorod Arrays Decorated with Carbon Quantum Dots toward Efficient Photoelectrochemical Water Splitting. ACS Appl. Mater. Interfaces 2019, 11 (21), 1916719175.

(16) Shi, W.; Guo, F.; Zhu, C.; Wang, H.; Li, H.; Huang, H.; Liu, Y.; Kang, Z. Carbon Dots Anchored on Octahedral $\mathrm{CoO}$ as a Stable Visible-Light-Responsive Composite Photocatalyst for Overall Water Splitting. J. Mater. Chem. A 2017, 5 (ii), 19800-19807.

(17) Martins, N. C. T.; Ângelo, J.; Girão, A. V.; Trindade, T.; Andrade, L.; Mendes, A. N-Doped Carbon Quantum Dots/TiO2 Composite with Improved Photocatalytic Activity. Appl. Catal. B Environ. 2016, 193, 67-74. 
(18) Wang, B.; Deng, Z.; Fu, X.; Li, Z. MoS2/CQDs Obtained by Photoreduction for Assembly of a Ternary MoS2/CQDs/ZnIn2S4 Nanocomposite for Efficient Photocatalytic Hydrogen Evolution under Visible Light. J. Mater. Chem. A 2018, 6 (40), 19735-19742.

(19) Feng, J.; Liu, G.; Yuan, S.; Ma, Y. Influence of Functional Groups on Water Splitting in Carbon Nanodots and Graphitic Carbon Nitride Composites: A Theoretical Mechanism Study. Phys. Chem. Chem. Phys. 2017, 19, 4997-5003.

(20) Luo, H.; Papaioannou, N.; Salvadori, E.; Roessler, M. M.; Ploenes, G.; Eck, E. R. H.; Tanase, L. C.; Feng, J.; Sun, Y.; Yang, Y.; Danaie, M.; Belen Jorge, A.; Sapelkin, A.; Durrant, J.; Dimitrov, S. D.; Titirici, M. Manipulating the Optical Properties of Carbon Dots by Fine-Tuning Their Structural Features. ChemSusChem 2019, 12 (19), 4335-4335.

(21) Shi, R.; Li, Z.; Yu, H.; Shang, L.; Zhou, C.; Waterhouse, G. I. N.; Wu, L. Z.; Zhang, T. Effect of Nitrogen Doping Level on the Performance of N-Doped Carbon Quantum Dot/TiO2 Composites for Photocatalytic Hydrogen Evolution. ChemSusChem 2017, 10 (22), 4650-4656.

(22) Yan, M.; Hua, Y.; Zhu, F.; Gu, W.; Jiang, J.; Shen, H.; Shi, W. Fabrication of Nitrogen Doped Graphene Quantum Dots-BiOI/MnNb 2 O 6 p-n Junction Photocatalysts with Enhanced Visible Light Efficiency in Photocatalytic Degradation of Antibiotics. Appl. Catal. B Environ. 2017, 202, 518-527.

(23) Sk, M. A.; Ananthanarayanan, A.; Huang, L.; Lim, K. H.; Chen, P. Revealing the Tunable Photoluminescence Properties of Graphene Quantum Dots. J. Mater. Chem. C 2014, 2 (34), 6954-6960. 
(24) Otyepka, M.; Kalytchuk, S.; Rogach, A. L.; Zbořil, R.; Sudolská, M.; Nachtigallová, D.; Holá, K. Graphitic Nitrogen Triggers Red Fluorescence in Carbon Dots. ACS Nano 2017, $11(12), 12402-12410$.

(25) Zhang, Y. Q.; Ma, D. K.; Zhang, Y. G.; Chen, W.; Huang, S. M. N-Doped Carbon Quantum Dots for TiO2-Based Photocatalysts and Dye-Sensitized Solar Cells. Nano Energy 2013, 2 (5), 545-552.

(26) Liang, Z.; Hou, H.; Fang, Z.; Gao, F.; Wang, L.; Chen, D.; Yang, W. Hydrogenated TiO 2 Nanorod Arrays Decorated with Carbon Quantum Dots toward Efficient Photoelectrochemical Water Splitting. ACS Appl. Mater. Interfaces 2019, 11 (21), 1916719175.

(27) Martindale, B. C. M.; Hutton, G. A. M.; Caputo, C. A.; Prantl, S.; Godin, R.; Durrant, J. R.; Reisner, E. Enhancing Light Absorption and Charge Transfer Efficiency in Carbon Dots through Graphitization and Core Nitrogen Doping. Angew. Chemie - Int. Ed. 2017, 56, 6459-6463.

(28) Hu, R.; Li, L.; Jin, W. J. Controlling Speciation of Nitrogen in Nitrogen-Doped Carbon Dots by Ferric Ion Catalysis for Enhancing Fluorescence. Carbon N. Y. 2017, 111, 133-141.

(29) Xie, S.; Su, H.; Wei, W.; Li, M.; Tong, Y.; Mao, Z. Remarkable Photoelectrochemical Performance of Carbon Dots Sensitized $\mathrm{TiO}_{2}$ under Visible Light Irradiation. J. Mater. Chem. A 2014, 2 (39), 16365-16368.

(30) Yang, Y.; Cui, J.; Zheng, M.; Hu, C.; Tan, S.; Xiao, Y.; Yang, Q.; Liu, Y. One-Step Synthesis of Amino-Functionalized Fluorescent Carbon Nanoparticles by Hydrothermal 
Carbonization of Chitosan. Chem. Commun. 2012, 48, 380-382.

(31) Zhang, D.-W.; Papaioannou, N.; David, N. M.; Luo, H.; Gao, H.; Tanase, L. C.; Degousée, T.; Samorì, P.; Sapelkin, A.; Fenwick, O.; Titirici, M.-M.; Krause, S. Photoelectrochemical Response of Carbon Dots (CDs) Derived from Chitosan and Their Use in Electrochemical Imaging. Mater. Horizons 2018, 5, 423-428.

(32) Marinovic, A.; Kiat, L. S.; Dunn, S.; Titirici, M. M.; Briscoe, J. Carbon-Nanodot Solar Cells from Renewable Precursors. ChemSusChem 2017, 10 (5), 1004-1013.

(33) Shu, C.-K. Degradation Products Formed from Glucosamine in Water. J. Agric. Food Chem. 1998, 46 (3), 1129-1131.

(34) Ortega-Liebana, M. C.; Chung, N. X.; Limpens, R.; Gomez, L.; Hueso, J. L.; Santamaria, J.; Gregorkiewicz, T. Uniform Luminescent Carbon Nanodots Prepared by Rapid Pyrolysis of Organic Precursors Confined within Nanoporous Templating Structures. Carbon N. Y. 2017, 117, 437-446.

(35) Yang, M.; Li, B.; Zhong, K.; Lu, Y. Photoluminescence Properties of N-Doped Carbon Dots Prepared in Different Solvents and Applications in PH Sensing. J. Mater. Sci. 2018, 53, $2424-2433$.

(36) Santos, C. I. M.; Mariz, I. F. A.; Pinto, S. N.; Gonçalves, G.; Bdikin, I.; Marques, P. A. A. P.; Neves, M. G. P. M. S.; Martinho, J. M. G.; Maçôas, E. M. S. Selective Two-Photon Absorption in Carbon Dots: A Piece of the Photoluminescence Emission Puzzle. Nanoscale 2018, 10 (26), 12505-12514.

(37) Strauss, V.; Margraf, J. T.; Dolle, C.; Butz, B.; Nacken, T. J.; Bauer, W.; Peukert, W.; 
Spiecker, E.; Clark, T.; Guldi, D. M. Carbon Nanodots - Towards a Comprehensive Understanding of Their Photoluminescence. J. Am. Chem. Soc. 2014, 49, 17308-17316.

(38) Sudolská, M.; Dubecký, M.; Sarkar, S.; Reckmeier, C. J.; Zbořil, R.; Rogach, A. L.; Otyepka, M. Nature of Absorption Bands in Oxygen-Functionalized Graphitic Carbon Dots. J. Phys. Chem. C 2015, 119, 13369-13373.

Li, Y.; Li, P.; Wang, J.; Yang, Y.; Yao, W.; Wei, Z.; Wu, J.; Yan, X.; Xu, X.; Liu, Y.; Zhu, Y. Water Soluble Graphitic Carbon Nitride with Tunable Fluorescence for Boosting BroadResponse Photocatalysis. Appl. Catal. B Environ. 2018, 225 (November 2017), 519-529.

(40) Sahu, S.; Behera, B.; Maiti, T. K.; Mohapatra, S. Simple One-Step Synthesis of Highly Luminescent Carbon Dots from Orange Juice: Application as Excellent Bio-Imaging Agents. Chem. Commun. 2012, 48, 8835-8837.

(41) Guin, J. P.; Guin, S. K.; Debnath, T.; Ghosh, H. N. Chemically Clean Single-Step OxidoReductive Synthesis of Green Luminescent Graphene Quantum Dots as Impending Electrocatalyst. Carbon N. Y. 2016, 109, 517-528.

(42) Shi, X. F.; Xia, X. Y.; Cui, G. W.; Deng, N.; Zhao, Y. Q.; Zhuo, L. H.; Tang, B. Multiple Exciton Generation Application of PbS Quantum Dots in $\mathrm{ZnO} @ \mathrm{PbS} / \mathrm{Graphene}$ Oxide for Enhanced Photocatalytic Activity. Appl. Catal. B Environ. 2015, 163, 123-128.

(43) Shi, X.; Kim, S.; Fujitsuka, M.; Majima, T. In Situ Observation of NiS Nanoparticles Depositing on Single TiO2 Mesocrystal for Enhanced Photocatalytic Hydrogen Evolution Activity. Appl. Catal. B Environ. 2019.

(44) Lee, K.; Yoon, H.; Ahn, C.; Park, J.; Jeon, S. Strategies to Improve the Photocatalytic 
Activity of TiO 2:3D Nanostructuring and Heterostructuring with Graphitic Carbon Nanomaterials. Nanoscale 2019, 11 (15), 7025-7040.

(45) Chen, Z.; Dinh, H. N.; Miller, E. Photoelectrochemical Water Splitting: Standards, Experimental Methods, and Protocols; Springer, 2013.

(46) Wang, H.; An, T.; Selloni, A. Effect of Reducible Oxide-Metal Cluster Charge Transfer on the Structure and Reactivity of Adsorbed Au and Pt Atoms and Clusters on Anatase TiO2. J. Chem. Phys. 2017, 146 (18), 184703.

(47) Nie, Y. C.; Yu, F.; Wang, L. C.; Xing, Q. J.; Liu, X.; Pei, Y.; Zou, J. P.; Dai, W. L.; Li, Y.; Suib, S. L. Photocatalytic Degradation of Organic Pollutants Coupled with Simultaneous Photocatalytic H2 Evolution over Graphene Quantum Dots/Mn-N-TiO2/g-C3N4 Composite Catalysts: Performance and Mechanism. Appl. Catal. B Environ. 2018, 227 (October 2017), 312-321.

(48) Tian, J.; Leng, Y.; Zhao, Z.; Xia, Y.; Sang, Y.; Hao, P.; Zhan, J.; Li, M.; Liu, H. Carbon Quantum Dots/Hydrogenated TiO2nanobelt Heterostructures and Their Broad Spectrum Photocatalytic Properties under UV, Visible, and near-Infrared Irradiation. Nano Energy 2015, 11, 419-427.

(49) Yu, L.; Shao, Y.; Li, D. Direct Combination of Hydrogen Evolution from Water and Methane Conversion in a Photocatalytic System over Pt/TiO2. Appl. Catal. B Environ. 2017, 204, 216-223.

(50) Xu, Y.; Zhang, C.; Zhang, L.; Zhang, X.; Yao, H.; Shi, J. Pd-Catalyzed Instant Hydrogenation of TiO 2 with Enhanced Photocatalytic Performance. Energy Environ. Sci. 
2016, 9 (7), 2410-2417.

(51) D’Angelo, D.; Bongiorno, C.; Amato, M.; Deretzis, I.; La Magna, A.; Fazio, E.; Scalese, S. Oxygen Functionalities Evolution in Thermally Treated Graphene Oxide Featured by EELS and DFT Calculations. J. Phys. Chem. C 2017, 121 (9), 5408-5414.

(52) Rajender, G.; Kumar, J.; Giri, P. K. Interfacial Charge Transfer in Oxygen Deficient TiO2Graphene Quantum Dot Hybrid and Its Influence on the Enhanced Visible Light Photocatalysis. Appl. Catal. B Environ. 2018, 224 (October 2017), 960-972.

(53) Raziq, F.; Sun, L.; Wang, Y.; Zhang, X.; Humayun, M.; Ali, S.; Bai, L.; Qu, Y.; Yu, H.; Jing, L. Synthesis of Large Surface-Area g-C3N4 Comodified with MnOx and Au-TiO2 as Efficient Visible-Light Photocatalysts for Fuel Production. Adv. Energy Mater. 2018, 8 (3), 2-11.

(54) Tzeng, W. J.; Wu, M. L.; Lin, L. J.; Chang, H. Y. Chalcogenide Photosensitized Titania Nanotube Arrays. J. Alloys Compd. 2015, 651 (December 2015), 483-489.

(55) Goossens, A.; Schoonman, J. Mott-Schottky Analysis of Nanometer-Scale. J. Electrochem. Soc. 1997, 144 (5), 1723-1727.

(56) Luo, Z.; Wang, T.; Zhang, J.; Li, C.; Li, H.; Gong, J. Dendritic Hematite Nanoarray Photoanode Modified with a Conformal Titanium Dioxide Interlayer for Effective Charge Collection. Angew. Chemie - Int. Ed. 2017, 56 (42), 12878-12882.

(57) Kim, J. Y.; Jung, H. S.; No, J. H.; Kim, J. R.; Hong, K. S. Influence of Anatase-Rutile Phase Transformation on Dielectric Properties of Sol-Gel Derived TiO2 Thin Films. J. Electroceramics 2006, 16 (4), 447-451. 
(58) Kudo, A.; Miseki, Y. Heterogeneous Photocatalyst Materials for Water Splitting. Chem. Soc. Rev. 2009, 38 (1), 253-278.

(59) Ma, Z.; Zhang, Y.-L.; Wang, L.; Ming, H.; Li, H.; Zhang, X.; Wang, F.; Liu, Y.; Kang, Z.; Lee, S.-T. Bioinspired Photoelectric Conversion System Based on Carbon-Quantum-DotDoped Dye-Semiconductor Complex. ACS Appl. Mater. Interfaces 2013, 5 (11), 50805084.

(60) Liu, R.; Huang, H.; Li, H.; Liu, Y.; Zhong, J.; Li, Y.; Zhang, S.; Kang, Z. Metal Nanoparticle / Carbon Quantum Dot Composite as Photocatalyst for High Efficiency Cyclohexane Oxidation. Acs Catal. 2014, 4, 328-336.

(61) Scanlon, D. O.; Dunnill, C. W.; Buckeridge, J.; Shevlin, S. A.; Logsdail, A. J.; Woodley, S. M.; Catlow, C. R. A.; Powell, M. J.; Palgrave, R. G.; Parkin, I. P.; Watson, G. W.; Keal, T. W.; Sherwood, P.; Walsh, A.; Sokol, A. A. Band Alignment of Rutile and Anatase TiO2. Nat. Mater. 2013, 12 (9), 798-801.

(62) Kashiwaya, S.; Morasch, J.; Streibel, V.; Toupance, T.; Jaegermann, W.; Klein, A. The Work Function of TiO2. Surfaces 2018, 1 (1), 73-89.

(63) Saha, A.; Moya, A.; Kahnt, A.; Iglesias, D.; Marchesan, S.; Wannemacher, R.; Prato, M.; Vilatela, J. J.; Guldi, D. M. Interfacial Charge Transfer in Functionalized Multi-Walled Carbon Nanotube@TiO2 Nanofibres.Nanoscale 2017, 9 (23),7911-7921. 
Table of Contents

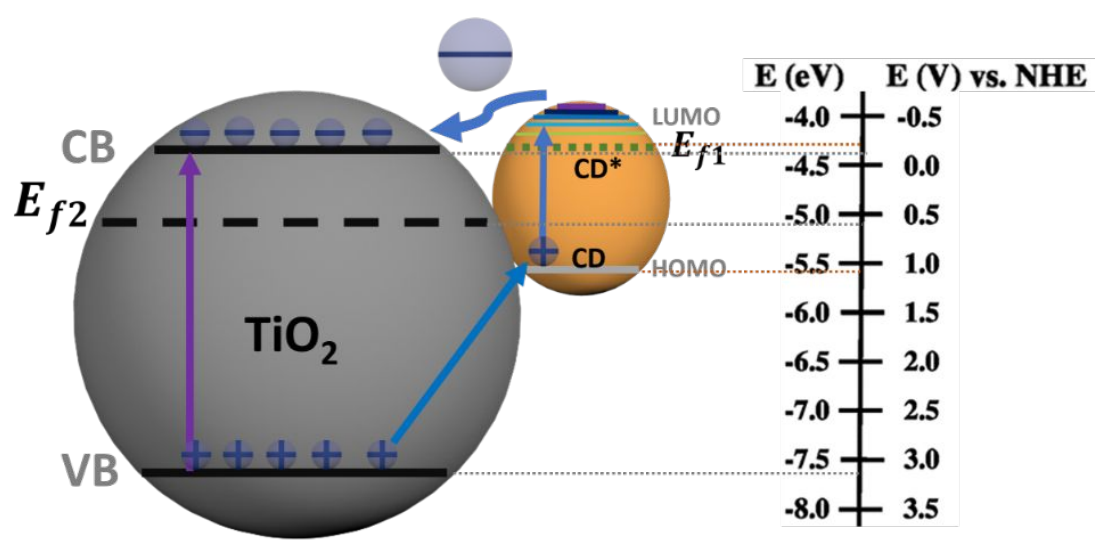

Type II heterojunction with well-resolved band positions 


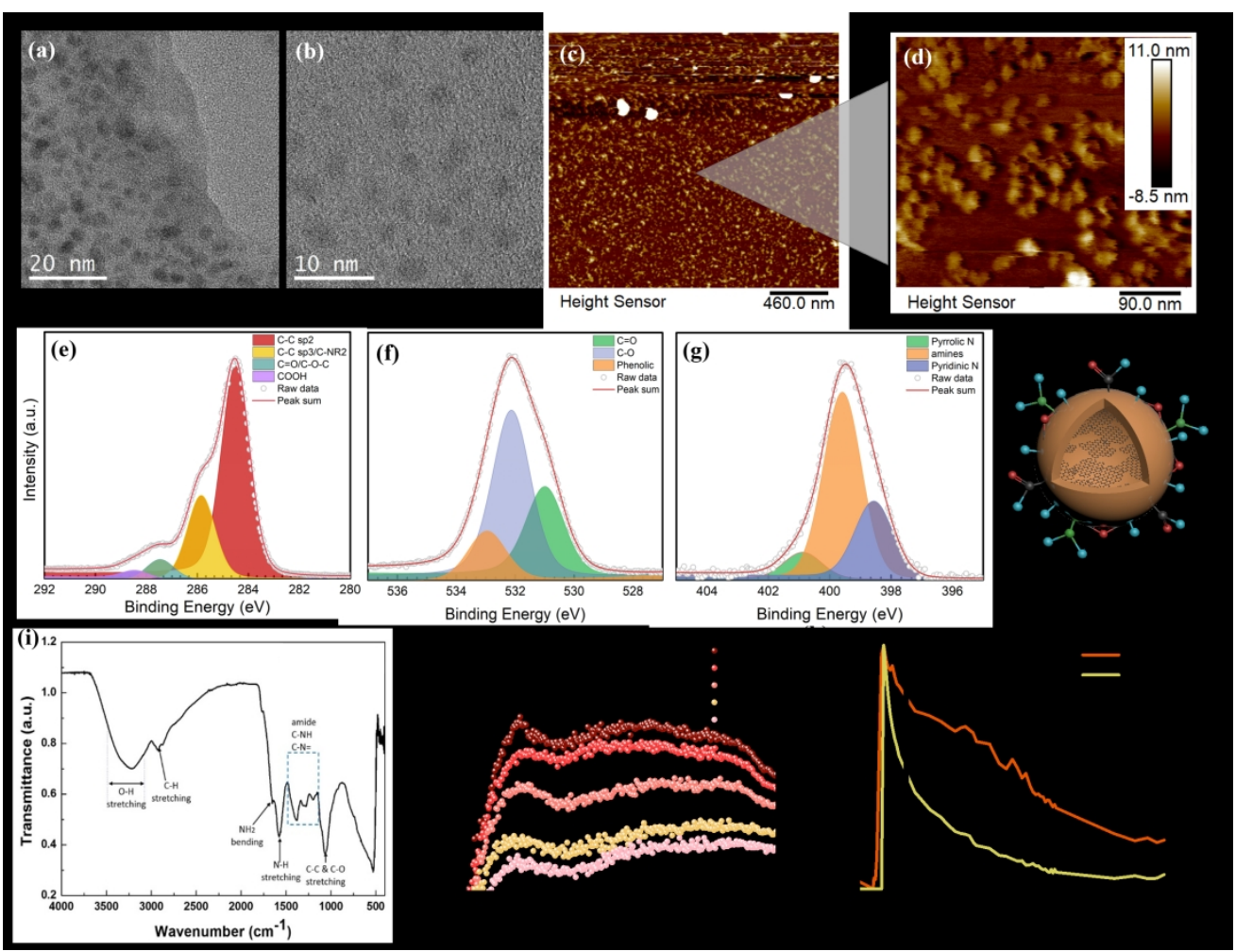

Figure 1 Structural features of as-prepared NCDs: TEM (a) and HR-TEM (b) images; (c) an overview AFM image on mica substrate (Z scale -6.0 to $7.9 \mathrm{~nm}$ ) and (d) high-resolution scanned image; XPS spectra: (e)

$\mathrm{C} 1 \mathrm{~s},(\mathrm{f}) \mathrm{O} 1 \mathrm{~s},(\mathrm{~g}) \mathrm{N} 1 \mathrm{~s}$ and corresponding FTIR (i) spectrum; (h) a schematic structure based on the characterizations (atoms in red: $\mathrm{O}$, green: $\mathrm{N}$ and blue: $\mathrm{H}$ ); $(\mathrm{j}$ ) fs-TAS spectra at different time decays and (k) normalized fs-TAS kinetics of NCDs and non-doped CDs measured at $500 \mathrm{~nm}$, samples were excited at $375 \mathrm{~nm}$.

$464 \times 353 \mathrm{~mm}(150 \times 150 \mathrm{DPI})$ 


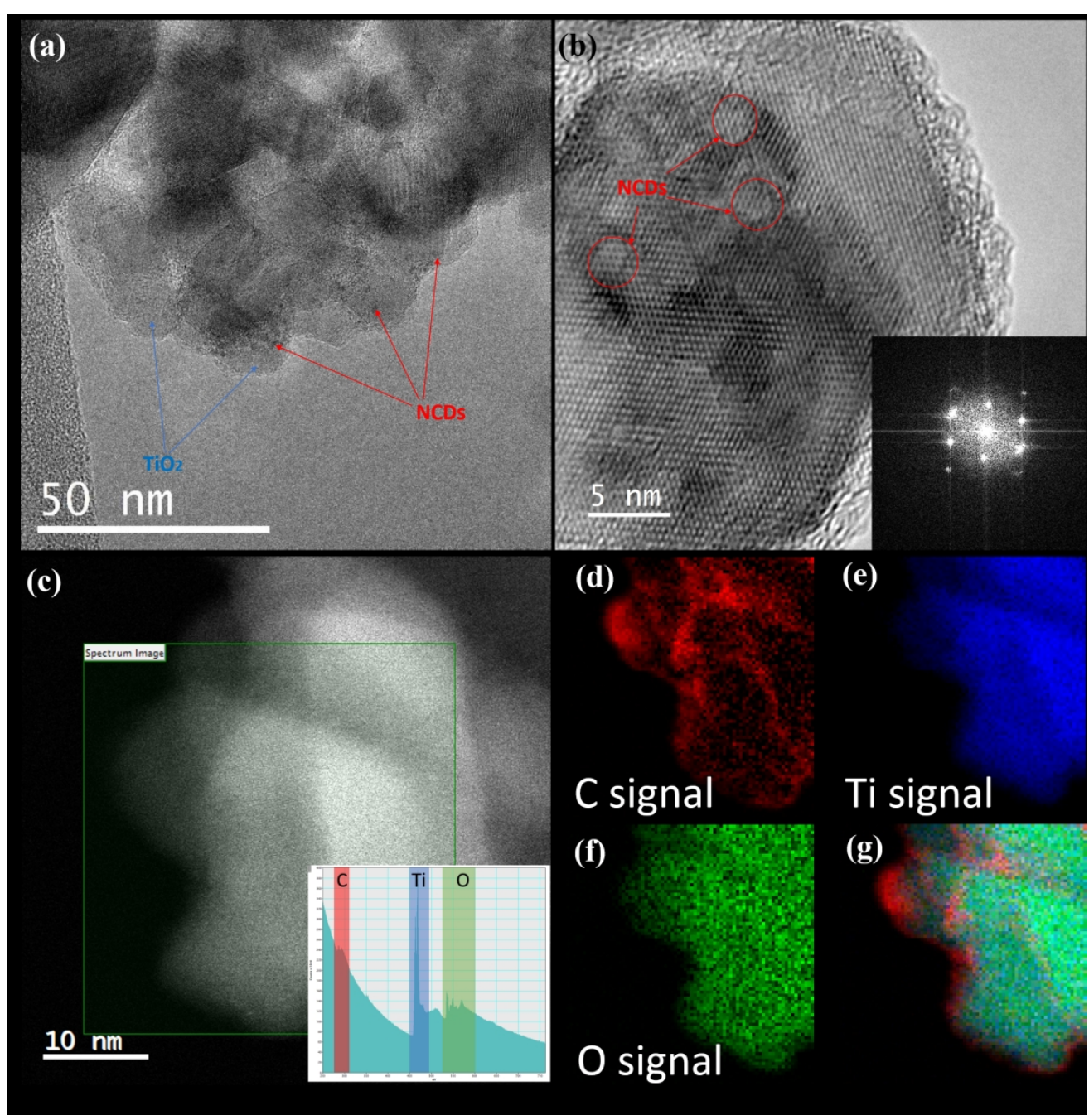

Figure 2 TEM (a) and HR-TEM (b) of NCDs/TiO2 (insert is the FFT patterns); (c) HAADF image of NCDs/TiO2 and corresponding EELS spectra (inserted). The single element maps derived from the spectra: (d) C signal, (e) Ti signal, ( $\mathrm{f}$ ) O signal and (g) colour mix (red: C, blue: Ti, green: 0 ).

$373 \times 380 \mathrm{~mm}(150 \times 150 \mathrm{DPI})$ 
Figure 3 Comparison of XPS survey spectra (a) and corresponding core level spectra (b) $\mathrm{Ti} 2 \mathrm{p}$ of the TiO2 and NCDs/TiO2 films; $O$ 1s spectra of (c) TiO2 and (d) NCDs/TiO2. (e) EELS spectra of TiO2 (black) and NCDs/TiO2 (red) and (f) FTIR signals.

$313 \times 366 \mathrm{~mm}(150 \times 150 \mathrm{DPI})$ 
Figure 4 optoelectronic properties of TiO2 and NCDs/TiO2 films: (a) UV-Vis absorption (inserted are the digital pictures of the films: left: TiO2, right: NCDs/TiO2); (b) tauc plot of TiO2 and NCDs/TiO2 with indirect band gap; LSV curves of (c) TiO2 and (d) NCDs/TiO2 under dark and light conditions; the chopped photocurrent response of the two samples under (e) full spectrum and (f) visible light $(\lambda>420 \mathrm{~nm})$ illumination; (g) EIS Nyquist plots under simulated solar light illumination ( $100 \mathrm{kHz}-0.1 \mathrm{~Hz}, 0.3 \mathrm{~V} \mathrm{vs}$. RHE, $100 \mathrm{~mW} \mathrm{cm-2)}$ and (h) Mott-Schottky plots with $10 \mathrm{kHz}$ frequency under dark condition at equilibrium.

$317 \times 506 \mathrm{~mm}(150 \times 150 \mathrm{DPI})$ 
Figure 5 (a) TCSPC decay profile of TiO2 (grey) and NCDs/TiO2 (red); (b) decay profiles of NCDs/TiO2 with (red) and without (grey)the presence of hole scavenger Na2S/Na2SO3. The excitation wavelength for all the experiments is $405 \mathrm{~nm}$, and the emission is recorded at $520 \mathrm{~nm}$.

$423 \times 176 \mathrm{~mm}(150 \times 150 \mathrm{DPI})$ 


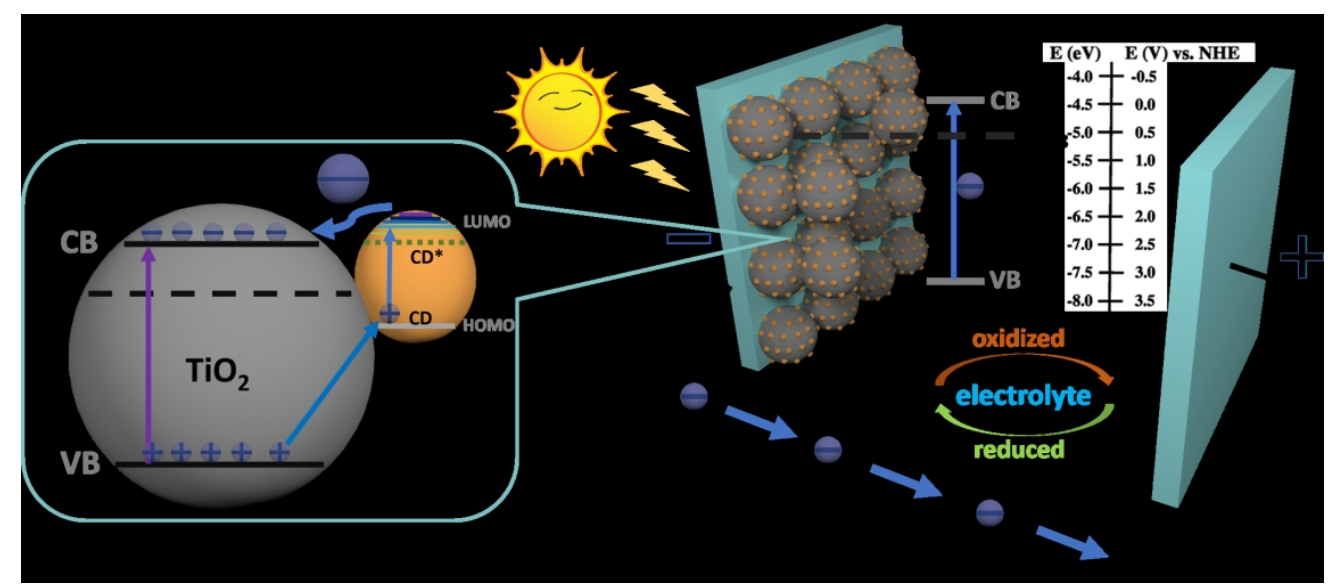

Figure 6 Proposed formation of the heterostructure with band alignments and charge transfer at the surface of TiO2 and NCDs under light irradiation.

$353 \times 154 \mathrm{~mm}(150 \times 150$ DPI $)$ 